\title{
Kinetic coupling of phosphate release, force generation and rate- limiting steps in the cross-bridge cycle
}

\author{
Robert Stehle $^{1}\left(\right.$ Chiara Tesi $^{2}$
}

Received: 5 July 2017 / Accepted: 12 September 2017 / Published online: 16 September 2017

(c) Springer International Publishing AG 2017

\begin{abstract}
A basic goal in muscle research is to understand how the cyclic ATPase activity of cross-bridges is converted into mechanical force. A direct approach to study the chemomechanical coupling between $P_{i}$ release and the force-generating step is provided by the kinetics of force response induced by a rapid change in $\left[\mathrm{P}_{\mathrm{i}}\right]$. Classical studies on fibres using caged- $\mathrm{P}_{\mathrm{i}}$ discovered that rapid increases in $\left[\mathrm{P}_{\mathrm{i}}\right]$ induce fast force decays dependent on final $\left[\mathrm{P}_{\mathrm{i}}\right]$ whose kinetics were interpreted to probe a fast force-generating step prior to $\mathrm{P}_{\mathrm{i}}$ release. However, this hypothesis was called into question by studies on skeletal and cardiac myofibrils subjected to $P_{i}$ jumps in both directions (increases and decreases in $\left[\mathrm{P}_{\mathrm{i}}\right]$ ) which revealed that rapid decreases in $\left[\mathrm{P}_{\mathrm{i}}\right]$ trigger force rises with slow kinetics, similar to those of calcium-induced force development and mechanically-induced force redevelopment at the same $\left[\mathrm{P}_{\mathrm{i}}\right]$. A possible explanation for this discrepancy came from imaging of individual sarcomeres in cardiac myofibrils, showing that the fast force decay upon increase in $\left[\mathrm{P}_{\mathrm{i}}\right]$ results from so-called sarcomere 'give'. The slow force rise upon decrease in $\left[\mathrm{P}_{\mathrm{i}}\right]$ was found to better reflect overall sarcomeres cross-bridge kinetics and its $\left[\mathrm{P}_{\mathrm{i}}\right]$ dependence, suggesting that the force generation coupled to $P_{i}$ release cannot be separated from the rate-limiting transition. The reasons for the different conclusions achieved in fibre and myofibril studies are re-examined as the recent findings on cardiac myofibrils have fundamental consequences for the
\end{abstract}

Robert Stehle

Robert.Stehle@Uni-Koeln.de

1 Institute of Vegetative Physiology, University of Cologne, Robert Koch Str. 39, 50931 Cologne, Germany

2 Division of Physiology, Department of Experimental and Clinical Medicine, University of Florence, Viale Morgagni, 63, 50134 Firenze, Italy coupling between $\mathrm{P}_{\mathrm{i}}$ release, rate-limiting steps and force generation. The implications from $\mathrm{P}_{\mathrm{i}}$-induced force kinetics of myofibrils are discussed in combination with historical and recent models of the cross-bridge cycle.

Keywords Muscle contraction · Power stroke $\cdot$ Tension redevelopment $\cdot$ Tension recovery $\cdot$ Myofibril force kinetics $\cdot$ Sarcomere dynamics

\section{Force generation during the cross-bridge ATPase cycle: an open question}

Contraction of skeletal and cardiac muscle is driven by the cross-bridge ATPase cycle. The steps generating the force and displacement in this cycle, also called the power strokes, are of particular interest. How force-generating step(s) are coupled to chemical steps in the ATPase cycle, i.e., the chemo-mechanical coupling of muscle contraction, is a central question in basic muscle research that has been continuously investigated in biochemical, biomechanical and structural studies from the molecular to the muscle level (Cooke 1997; Gordon et al. 2000; Huxley 2004; Steffen and Sleep 2004; Takagi et al. 2004; Geeves and Holmes 2005; Thomas et al. 2009; Houdusse and Sweeney 2016). An early model (Lymn and Taylor 1971) describing chemo-mechanical coupling is depicted in Fig. 1a. In the Lymn-Taylor model, force generation and product $\left(\mathrm{P}_{\mathrm{i}}\right.$ and ADP) release from the crossbridge are merged to one-step. Subsequently, the major free energy change as well as the major transition from weak to strong actin binding states in the ATPase cycle in the cycle was assigned to the release of $\mathrm{P}_{\mathrm{i}}$ that precedes ADP release (Trentham et al. 1972; Eisenberg and Greene 1980). These findings lead to the view in the 1980s that force-generation is coupled to $P_{i}$ release (Eisenberg and Hill 1985). Neither 


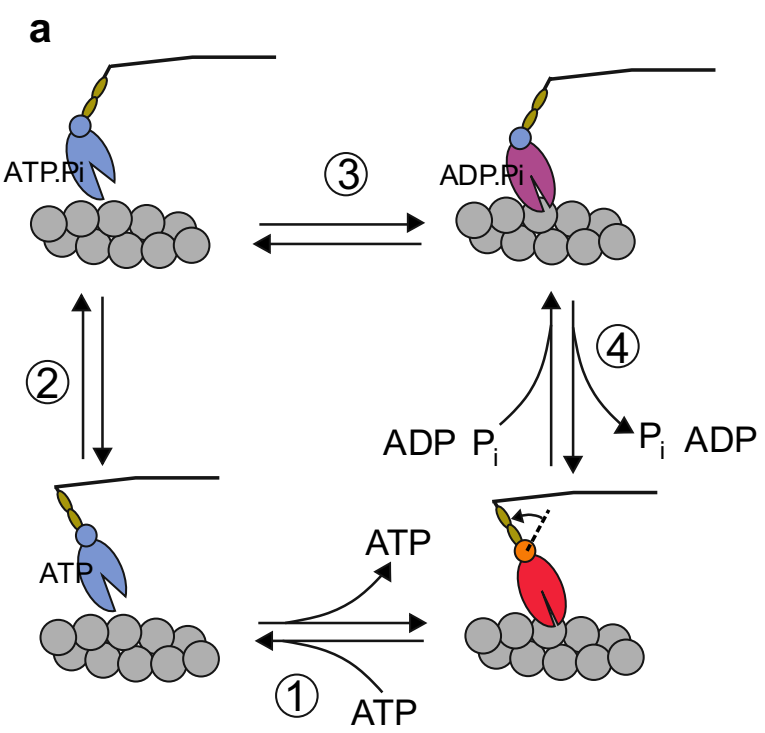

Fig. 1 Sequence of rate-limiting transitions, force-generating steps and $\mathrm{P}_{\mathrm{i}}$ release in different models of the cross-bridge cycle. a Fourstate model of Lymn and Taylor. b Extended six-state model implied from the fast force decay upon increase of $\left[\mathrm{P}_{\mathrm{i}}\right]$. In both models, ATPbinding induces rapid detachment of the cross-bridge from actin by opening the actin binding cleft (step 1, (1), thereby stabilizing myosin in non-force-generating states with low actin affinity (light grey coloured heads, blue colour in online version). The cross-bridge recovers the power stroke by tilting of its lever arm, and hydrolyses ATP (step 2, (2). Crucial for initiation of force generation is the preceding formation of a stereospecific, pre-force-generating AM.ADP.P ${ }_{i}$ state (mid grey coloured head, pink in online version) with a largely closed actin binding cleft (step 3, (3). Subsequent force generation is indicated by the tilt of the lever arm and the shift to dark grey colour of head (red colour in online version) and the converter domain (step 4, (4). In a the four-state Lymn-Taylor model, the force-generating step is inseparably coupled with release of products $\left(\mathrm{P}_{\mathrm{i}}\right.$ and

the Lymn-Taylor nor the Eisenberg-Hill model differentiates whether force is generated before, during or after release of $\mathrm{P}_{\mathrm{i}}$. From chemical and physical principles, the view of a direct coupling, i.e., a one-step mechanism of force-generation coupled to $\mathrm{P}_{\mathrm{i}}$ release might be simplistic. The classical view of ligand binding/dissociation is that of a rapid, diffusion-limited equilibrium that then induces a more or less slower conformational change of the enzyme. Accordingly, a two-step process of force generation coupled to $P_{i}$ release is expected, i.e., a force-generating step occurring before or after a rapid $P_{i}$ release. Furthermore, there might be additional slow steps in the cycle that limit the rate of

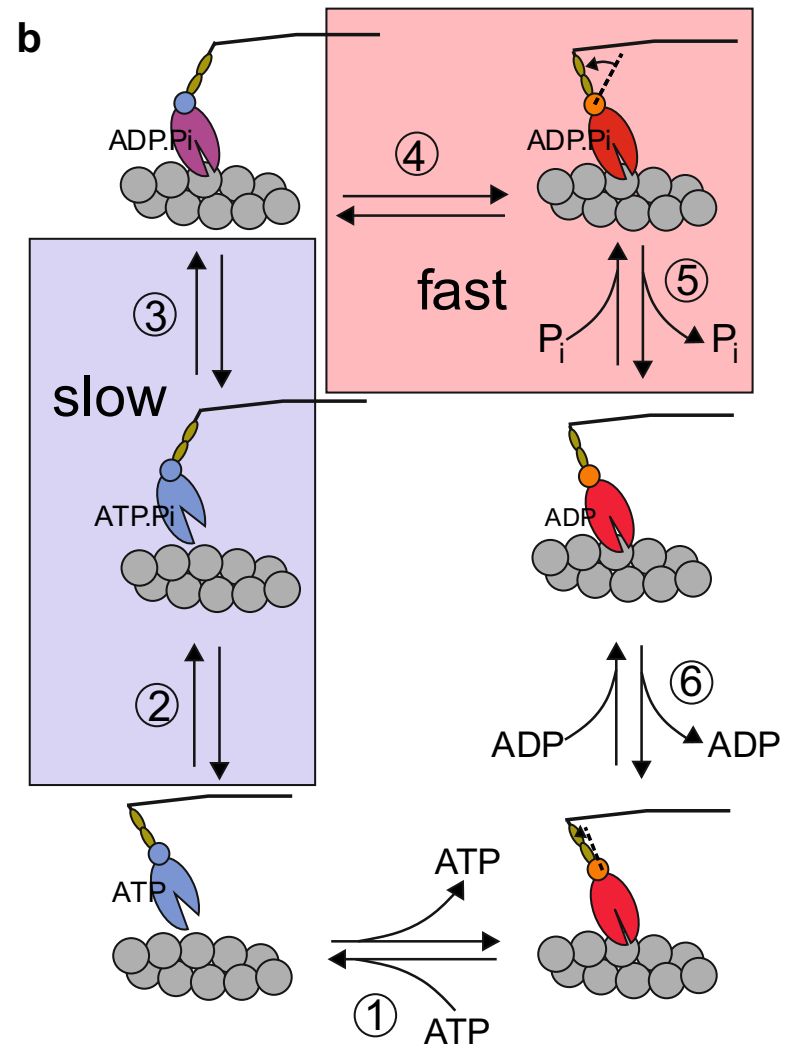

ADP). Further, the model does not indicate which step(s) limit(s) the transition of cross-bridges to the force state, i.e., the transition rate $f$ : ATP hydrolysis (2), formation of the pre-force-generating AM.ADP. $\mathrm{P}_{\mathrm{i}}$ state (3) or product release (4). b In the extended six-state model, a fast major force-generating step (4) occurs prior to rapid $P_{i}$ release (step 5, 5) and a further minor force-generating step with the release of ADP (step 6, (6). Because (4) and (5) present fast steps, $f$ must be limited by (3) or (2). The forward transition of cross-bridges to weakly bound, non-force-generating states (rate constant $g$ ) is limited by the load-dependent step 6 (6). In absence of load, (6) is fast. Under high load as during isometric contraction, (6) is slow, so that $g$ becomes similar or even lower than $f$. The isometric ATPase rate (ATPase $1 / f+1 / g$ ) is mainly limited by $g$, whereas the rate of force redevelopment $\left(k_{\mathrm{TR}} \sim f+g\right)$ is also determined by $f$. Models modified from (Lymn and Taylor 1971) (a) and (Dantzig et al. 1992; Capitanio et al. 2006; Houdusse and Sweeney 2016) (b). (Color figure online)

force generation. The rate constant of the transition that limits the turnover of cross-bridges into force-generating states is termed $f$. If $f$ represents the kinetics of an intrinsically slow process whereas force-generation and $\mathrm{P}_{\mathrm{i}}$ release are intrinsically fast steps, $f$ must belong to different step(s). The minimalist model of Lymn-Taylor was therefore refined by inserting additional steps and states, based on many kinetic and structural studies (Chalovich and Eisenberg 1982; Pate and Cooke 1989; Millar and Homsher 1990; Kawai and Halvorson 1991; Dantzig et al. 1992; Davis and Rodgers 1995; Cooke 1997; Brenner and Chalovich 1999; Gordon et al. 2000; Martin et al. 2004; Takagi et al. 2004; Geeves and 
Holmes 2005; Capitanio et al. 2006; Siththanandan et al. 2006; Caremani et al. 2013; Smith 2014; Dong and Chen 2016; Geeves 2016; Houdusse and Sweeney 2016; Mansson 2016; Mijailovich et al. 2017).

To date numerous models of the cross-bridge cycle exist, which differ in many details. In particular, the sequence of the $\mathrm{P}_{\mathrm{i}}$ release and the force-generating step is still an open debate (Llinas et al. 2015; Mansson et al. 2015; Muretta et al. 2015; Houdusse and Sweeney 2016). Furthermore, the reaction(s) and structural change(s) contributing to the ratelimiting transition $f$ remain to be defined. Clarifying these issues is important for understanding the basic mechanism of force generation and its targeted alteration. For example, with regard to search and design of molecules targeting force production by stabilizing cross-bridges in certain chemical states, it is essential to know whether AM.ADP. $\mathrm{P}_{\mathrm{i}}$-intermediate(s) prior to $\mathrm{P}_{\mathrm{i}}$ release can generate force in muscle contraction. Furthermore, understanding the nature of the transitions that determine $f$ is essential for targeted interventions of rate-limiting steps, which provide an efficient way to tune force generation. This review focusses on the significance of mechanical studies for defining the sequence and mechanism of the rate-limiting transition $f$, the force-generating step and the $P_{i}$ release in the cross-bridge cycle.

\section{Kinetics of rate-limiting transitions in the cross-bridge cycle}

To separate the force-generating step from the rate-limiting transition $f$, first one needs to know the value of $f$. The first model of the cross-bridge cycle by A.F. Huxley consisted of only two states, a non-force-generating and a force-generating state, and two rate constants for forward cycling, the rate constant $f$ for entering the force-generating state and the rate constant $g$ for leaving the force-generating state (Huxley 1957). In this model, the rate-limiting transition and the force-generating step are combined in a single step and force is proportional to $f /(f+g)$ and ATPase proportional to $f \cdot g /(f+g)$ or $1 / f+1 / g$. In the line of this seminal and prescient model, a fundamental contribution was given by $\mathrm{B}$. Brenner and coworkers, based on the findings that: (1) the observed rate constant of mechanically-induced, maximally $\mathrm{Ca}^{2+}$ activated force redevelopment, $k_{\mathrm{TR}}$ probes cross-bridge turnover kinetics and reflects the sum of $f$ and $g$ (Brenner and Eisenberg 1986); and (2) the $\mathrm{Ca}^{2+}$ regulation of force generation and ATPase of isometric contracting fibres underlies rate-modulation of $f$, whereby $f$ gradually increases while $g$ remains constant with increasing the $\left[\mathrm{Ca}^{2+}\right]$ (Brenner 1988). From the change of $f$ it was clear that it does not present a fixed intrinsic rate constant of a single step but an apparent rate constant, termed $f_{\text {app }}$, of at least two steps. Brenner noted that rate-modulation of $f_{\text {app }}$ can be explained by assuming that 'turned on and turned off forms of the regulated actin units are in a dynamic equilibrium with fast rate constants compared to cross-bridge turnover' and ' $\mathrm{P}_{\mathrm{i}}$ release only occurs when cross-bridges are attached to the turned on form of actin'. Basically, $f_{\text {app }}$ might result from a forward step and a foregoing faster, $\mathrm{Ca}^{2+}$-regulated equilibrium modulating the initial state, $A_{0}$, of this forward step. The observed $f_{\text {app }}$ in the experiment depends on the intrinsic rate constant $f^{\rightarrow}$ of the forward step as well as on the occupancy $\left[A_{0}\right]$ of the initial state. Noteworthy, $f \rightarrow$ must not be slow if only very few cross-bridges are capable to undergo the forward step. Thus, it remains open whether $f^{\hookrightarrow}$ is slow and $\left[A_{0}\right]$ is high or whether $f^{\rightarrow}$ is fast and $\left[A_{0}\right]$ is low. The individual contributions of $\left[A_{0}\right]$ and $f^{\rightarrow}$ can be only modelled but not separately measured. Furthermore, the structural and biochemical changes contributing to the rate limiting transition $f$ and its $\mathrm{Ca}^{2+}$-modulated substitute $f_{\text {app }}$ remain unclear. At least, the individual contributions of $f_{\text {app }}$ and $g_{\text {app }}$ can be derived from combined measurements of $k_{\mathrm{TR}}$, force and ATPase at maximally activating $\left[\mathrm{Ca}^{2+}\right]$ (Brenner 1988), from the $\mathrm{Ca}^{2+}$ dependence of force and $k_{\mathrm{TR}}$ (de Tombe and Stienen 2007), or from combined measurement of $k_{\mathrm{TR}}$, reflecting $f_{\mathrm{app}}+g_{\mathrm{app}}$, and the force decay of the initial relaxation phase following rapid $\mathrm{Ca}^{2+}$ removal during which all sarcomeres relax isometric. The rate constant of this initial, slow, linear force decay, called 'slow $k_{\mathrm{REL}}$ ' or ' $k_{\text {LIN }}$ ' reflects $g_{\text {app }}$ (Poggesi et al. 2005).

Changes in the rate-limiting transitions strongly affect energy consumption. Any modification of $f_{\text {app }}$ proportionally affects force and ATPase so that the ratio of force per ATPase, called tension cost, remains constant. In contrast, tension cost is proportional to $g_{\text {app }}$, as an increase of $g_{\text {app }}$ decreases force but increases ATPase. Classical mechanical studies in single intact fibres at maximally activating $\left[\mathrm{Ca}^{2+}\right]$ (Huxley 1957) proved that $g_{\text {app }}$ markedly increases with shortening velocity. Strikingly, force is highly $\left[\mathrm{P}_{\mathrm{i}}\right]$-dependent, while maximum shortening velocity is hardly affected by the $\left[\mathrm{P}_{\mathrm{i}}\right]$ (Cooke et al. 1988; Caremani et al. 2015). These results indicate that $P_{i}$ neither reduces force by increasing $g_{\text {app }}$ nor by decreasing $f_{\text {app }}$, as proved by the positive effect of $\left[\mathrm{P}_{\mathrm{i}}\right]$ on $k_{\mathrm{TR}}$. These results imply that instead of affecting the forward turnover rate $f_{\text {app }}, \mathrm{P}_{\mathrm{i}}$ promotes the reverse turnover rate $f_{\text {app }}^{-}$. This view is supported by oxygen exchange measurements indicating that in isometric contracting muscle fibres, all chemical reactions from an AM.ADP-state back to an AM.ATP state are readily reversible (Hibberd et al. 1985b; Webb et al. 1986), reviewed in (Takagi et al. 2004). Thus, force reduction by $P_{i}$ would result from $\mathrm{P}_{\mathrm{i}}$ binding to an AM.ADP-state and reverse turnover via $f_{\text {app }}^{-}$. This $\left[\mathrm{P}_{\mathrm{i}}\right]$-dependent reverse turnover by $f_{\text {app }}^{-}$provides an additional exit from force-generating states to the 
$\left[\mathrm{P}_{\mathrm{i}}\right]$-independent exit route via forward turnover by $g_{\text {app }}$. Based on the view that force redevelopment reflects overall re-distribution of cross-bridges determined by all rate-limiting transitions, in presence of $\mathrm{P}_{\mathrm{i}}, k_{\mathrm{TR}}=f_{\text {app }}+g_{\text {app }}+f_{\text {app }}^{-}$. Recently, (Wang and Kawai 2013) reinterpreted $k_{\mathrm{TR}}$ to reflect only $g_{\text {app }}$, instead of the classical view of $k_{\mathrm{TR}}$ reflecting the sum of all rate-limiting transitions. However, the finding that $\mathrm{P}_{\mathrm{i}}$ accelerates the rate of $\mathrm{Ca}^{2+}$-induced force development, $k_{\mathrm{ACT}}$ or mechanically-induced force redevelopment, $k_{\mathrm{TR}}$ in fast skeletal (Hibberd et al. 1985a; Millar and Homsher 1990; Regnier et al. 1995; Regnier and Homsher 1998), slow skeletal (Millar and Homsher 1992; Wahr et al. 1997) and cardiac muscles (Araujo and Walker 1996; Edes et al. 2007) while it decreases force in proportion to the number of forcegenerating cross-bridges (Kawai and Halvorson 1991; Caremani et al. 2008) is strong evidence against this reinterpretation. Interestingly, in fast muscle, $\mathrm{P}_{\mathrm{i}}$ reduces isometric ATPase to a lesser extent than force (Webb et al. 1986; Bowater and Sleep 1988; Cooke et al. 1988) while the effect is very similar in slow muscle (Potma et al. 1995; Kerrick and Xu 2004). The change of the force-ATPase ratio or tension cost by $\left[\mathrm{P}_{\mathrm{i}}\right]$ poses a complication for the modeling of $\mathrm{P}_{\mathrm{i}}$ effect on chemo-mechanical coupling, which is still under debate (Pate and Cooke 1989; Linari et al. 2010). In summary, $\mathrm{P}_{\mathrm{i}}$ release is reversible and $\left[\mathrm{P}_{\mathrm{i}}\right]$-dependent rebinding of $P_{i}$ accelerates the redistribution amongst force-generating and non-force-generating/detached states by promoting backwards cycling.

While force redevelopment reports rate-limiting transitions in the cross-bridge ATPase cycle, force generation per se is a fast process. At the single molecule level, force rapidly develops upon attachment of myosin to actin filaments in single molecule force assays like the laser trap (Finer et al. 1994; Veigel et al. 1998; Takagi et al. 2004). Also the cross-bridge ensemble in muscle fibres can rapidly regenerate force (within several msec) after small length change perturbations (Ford et al. 1977; Kawai and Halvorson 1991; Lombardi et al. 1992; Colomo et al. 1994; Ranatunga et al. 2002; Linari et al. 2007) or pressure (Fortune et al. 1991) and temperature jumps (Davis and Rodgers 1995; Bershitsky and Tsaturyan 2002; Coupland and Ranatunga 2003). Albeit the phenomena of the rapid force recovery likely reflects a different mechanism of force generation uncoupled from or loosely coupled to the ATPase cycle (Davis and Rodgers 1995; Caremani et al. 2008, 2013), there is common consensus that not the force-generating step, but some other process or reaction, perhaps isomerization within a given force state, that limits the transition of cross-bridges to force-generating states in the ATPase cycle. To distinguish between the possible difference of force recovery and force generation coupled to ATPase cycling, the latter is termed here de novo force development. Overall, the observed broad spectra of force responses upon small and large perturbations of muscle preparations led to the hypothesis that slow transitions determine de novo force development reflected by $f$, while the force can be rapidly re-generated and thus the force-generating step per se could be fast.

\section{Refinement of the force-generating mechanism coupled to $P_{i}$ release in muscle fibres}

The one-step mechanism of force generation along with $P_{i}$ release had been accepted until the early 1990s, when seminal experiments on skinned muscle fibres using a new chemical compound, caged- $\mathrm{P}_{\mathrm{i}}$, produced in a new hypothesis of the two-step process for force generation (Takagi et al. 2004). Fibres were loaded with caged- $P_{i}$ and the caged compound activated by flash photolysis. The photolysis caused a rapid $(<1 \mathrm{~ms})$ increase in $\left[\mathrm{P}_{\mathrm{i}}\right]$ in the fibre, the so called $P_{i}$ jump, resulting in force responses with a major force reduction. The $\mathrm{P}_{\mathrm{i}}$-induced force response produced up to four kinetic phases (see Fig. 2b in Dantzig et al. 1992), albeit not all phases were observed in the other studies using caged- $\mathrm{P}_{\mathrm{i}}$ (Millar and Homsher 1992; Walker et al. 1992). The sudden increase of sarcoplasmic $\left[\mathrm{P}_{\mathrm{i}}\right]$ shifts cross-bridges backwards in the cycle because it promotes $P_{i}$ binding to the cross-bridge, i.e., the reversal of $P_{i}$ release. Phase 1 was a short lag of several msec that was attributed to $P_{i}$ binding to the AM.ADP-state and the formation of an AM.ADP.P $\mathrm{i}^{-}$ state that still generates force. Viewed in forward direction, this indicated that force is generated before $\mathrm{P}_{\mathrm{i}}$ release. Most attention was paid to phase 2 , a major exponential force decay whose kinetics were strongly $\left[\mathrm{P}_{\mathrm{i}}\right]$-dependent. The rate constant $k_{\mathrm{Pi}}$ of phase 2 was attributed to the kinetics of the force-generating process in the cycle and the hyperbolic form of $k_{\mathrm{Pi}}$ dependence on $\left[\mathrm{P}_{\mathrm{i}}\right]$ was also taken as a strong and final support to the two-step process for force generation. Beside the lag (phase 1) and the major decay (phase 2), a minor rise (phase 3 ) and a minor decay (phase 4) had been observed (Dantzig et al. 1992). Minor phases 3 and 4 were not studied as phase 3 was ascribed to secondary effects caused by caged compounds themselves and/or sarcomere dynamics while phase 4 was found to be highly variable and not $\left[\mathrm{P}_{\mathrm{i}}\right]$ dependent.

By the time it became possible to study $\mathrm{P}_{\mathrm{i}}$-induced force kinetics, the $k_{\mathrm{TR}}$-measurement was already established and the kinetics of the major force decay could be compared with the rate-limiting process $f_{\text {app }}$ probed by $k_{\mathrm{TR}}$. Importantly, the force decay of phase 2 was significantly faster than the force rise induced in the $k_{\mathrm{TR}}$-measurement. Thus, in fast skeletal fibres at $10-15{ }^{\circ} \mathrm{C}, k_{\mathrm{Pi}}$ was about $2-3$ times faster than $k_{\mathrm{TR}}$ measured at same [ $\mathrm{P}_{\mathrm{i}}$ ] (Millar and Homsher 1990; Walker et al. 1992). Using the caged- $P_{\mathrm{i}}$ method, $k_{\mathrm{Pi}}$ of phase 2 was found 2-3 times higher than $k_{\mathrm{TR}}$ also in cardiac 

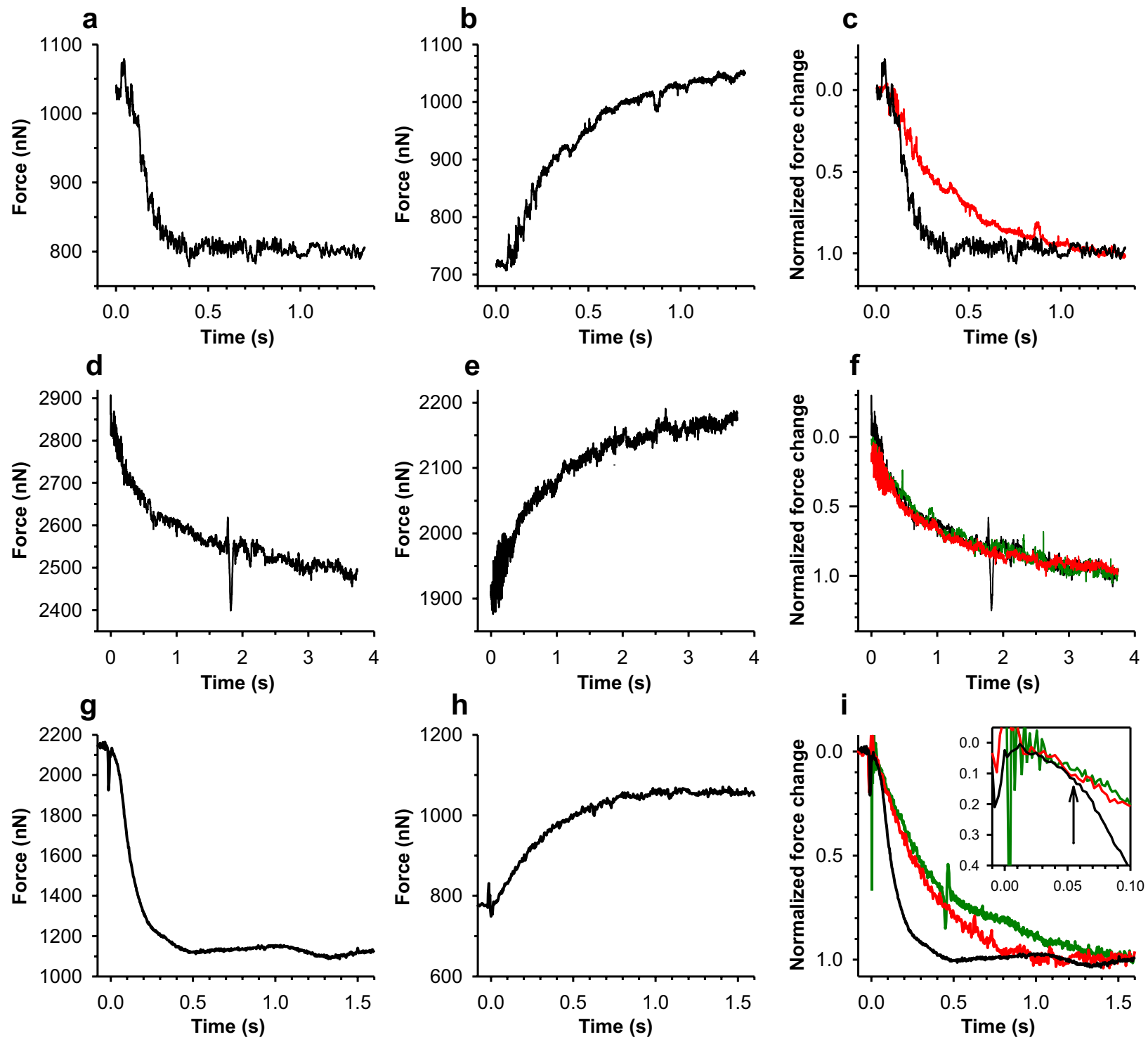

Fig. 2 Symmetry and asymmetry of force responses observed upon increases or decreases in $\left[\mathrm{P}_{\mathrm{i}}\right]$ to the same final $\left[\mathrm{P}_{\mathrm{i}}\right]$ during maximum $\mathrm{Ca}^{2+}$ activation ( $\mathrm{pCa} 4.5$ ). Force responses of myofibrils from fast skeletal muscle at $5{ }^{\circ} \mathrm{C}$ (upper row, a-c), slow skeletal muscle at $15{ }^{\circ} \mathrm{C}$ (mid row, $\mathbf{d}-\mathbf{f}$ ), and cardiac myofibrils at $10{ }^{\circ} \mathrm{C}$ (lower row, $\mathbf{g}-\mathbf{i})$ were induced by rapid increase of $\left[\mathrm{P}_{\mathrm{i}}\right]$ (left column, $\mathbf{a}, \mathbf{d}, \mathbf{g}$ ) or rapid decrease of $\left[\mathrm{P}_{\mathrm{i}}\right]$ (mid column, $\mathbf{b}, \mathbf{e}, \mathbf{h}$ ). At time $=0$, the $\left[\mathrm{P}_{\mathrm{i}}\right]$ was changed (in $\mathrm{mM}$ ) from 0.2 to 1 (a), 5 to 1 (b), 0.2 to 2 (d), 20 to 2 (e), 0.2 to $10(\mathbf{g})$, and 20 to $10(\mathbf{h})$. Graphs in the right column (c, f, i) illustrate force transients from the respective row after normalization to amplitude and direction, i.e., force rises were inverted to enable comparison of kinetics with force decays. Circles (red lines in online version) are normalized force changes upon decrease in $\left[\mathrm{P}_{\mathrm{i}}\right]$. Triangles (green lines in online version) are normalized force changes in $k_{\mathrm{TR}}$-measurements performed at the corresponding [ $\left.\mathrm{P}_{\mathrm{i}}\right]$, i.e. at the

muscle at $15{ }^{\circ} \mathrm{C}$ (Araujo and Walker 1996). This result was interpreted to mean that there is a fast force-generating step closely associated to $P_{i}$ release that can be dissected from the slower rate-limiting transitions reflected by $f$. The final $\left[\mathrm{P}_{\mathrm{i}}\right]$ in the $\mathrm{P}_{\mathrm{i}}$ jump experiments. Note the asymmetry of force rise and force decay when changing to the same $\left[\mathrm{P}_{\mathrm{i}}\right]$ in fast psoas (c), whereas there is symmetry in the slow soleus (f). In cardiac myofibrils, there is initial symmetry during upon the $\left[\mathrm{P}_{\mathrm{i}}\right]$ change (best seen by the magnification of the initial part in the inlet), turning to asymmetry at the time of the transition from the first, minor force decay to the second, major force decay upon increase of $\left[\mathrm{P}_{\mathrm{i}}\right]$ (black lined transient). The arrow marks the duration of phase $1\left(t_{+\mathrm{Pi}(1)}=57 \mathrm{msec}\right)$ obtained by fitting the black transient with the biphasic function used in (Stehle et al. 2002a; Stehle 2017). The similar slopes of the normalized force changes before $t_{+\mathrm{Pi}(1)}$ illustrate the symmetry of $k_{+\mathrm{Pi}(1)}$ and $k_{-\mathrm{Pi}}$ and similarity with $k_{\mathrm{TR}}$ (for more data, see (Stehle 2017) and Fig. 3c). Asymmetry starts with the onset of the major second phase (see higher values of $k_{+\mathrm{Pi}(2)}$ compared to and $k_{-\mathrm{Pi}}$ and $k_{\mathrm{TR}}$ in Fig. $3 \mathrm{c}$ ). (Color figure online)

$\left[\mathrm{P}_{\mathrm{i}}\right]$-dependence of the kinetics indicated that this forcegenerating step is a fast isomerization prior to $\mathrm{P}_{\mathrm{i}}$ release, i.e., that force generation occurs in the ADP. $P_{i}$-bound state of the cross-bridge. The forward and backward rate constant 

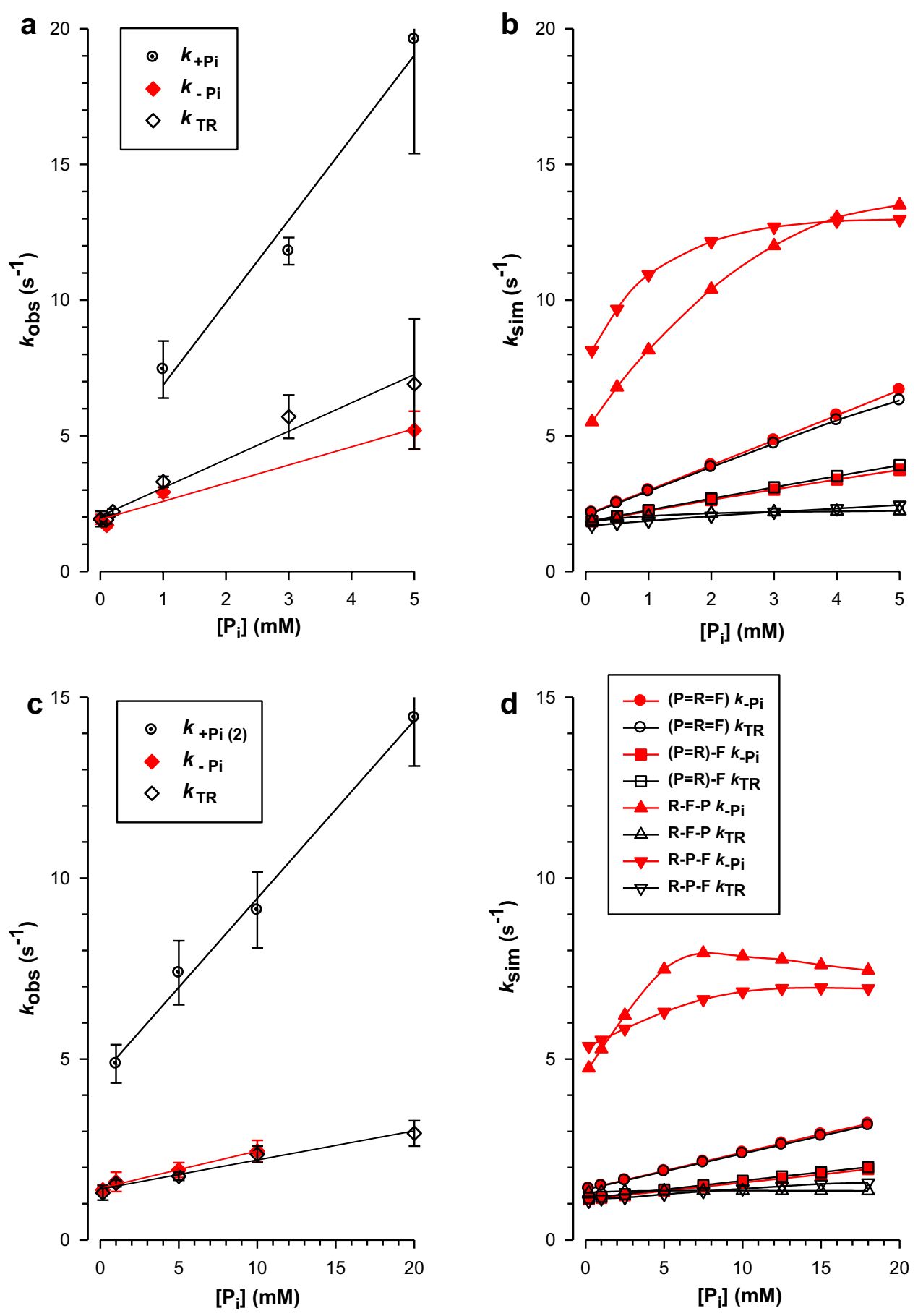

of this force-generating isomerization step were derived from the hyperbolic dependence of $k_{\mathrm{Pi}}$ versus the $\left[\mathrm{P}_{\mathrm{i}}\right]$. In fast skeletal muscle fibres, the forward rate constant of this step was markedly higher than $f_{\text {app }}$. In consequence, refined cross-bridge models consisted of a reversible, force-generating step that occurs after a slower, rate-limiting step or transition (related to $f$ ) and before rapid $\mathrm{P}_{\mathrm{i}}$ release in the cross-bridge cycle (Fig. 1b). The finding of the fast force decay after a jump increase in $\left[\mathrm{P}_{\mathrm{i}}\right]$ were convincing because

the kinetic behavior of the $\mathrm{P}_{\mathrm{i}}$ transient was consistent with the sequential reaction involving a rapid equilibrium of $P_{i}$ release/rebinding and a slower reversible force-generating step exhibiting a saturation as the substrate is increased. The sequence of these three key events in the cross-bridge cycle seemed to be solved even if contemporaneous caged$\mathrm{P}_{\mathrm{i}}$ studies in slow muscle cast a shadow on this hypothesis. Measurements of $k_{\mathrm{Pi}}$ and $k_{\mathrm{TR}}$ in soleus fibres at same $\left[\mathrm{P}_{\mathrm{i}}\right]$ and at maximally activating $\left[\mathrm{Ca}^{2+}\right]$ showed that $\mathrm{P}_{\mathrm{i}}$ release could 
4Fig. 3 Measured and simulated $\left[\mathrm{P}_{\mathrm{i}}\right]$-dependence of force kinetic parameters. a Rate constants obtained in experiments on fast skeletal rabbit psoas myofibrils (fs-mf) at $5{ }^{\circ} \mathrm{C}$. c Rate constants obtained in experiments on cardiac myofibrils (c-mf) from guinea pig left ventricle at $10^{\circ} \mathrm{C}$ (Stehle 2017). Experimentally observed rate constants in a and $\mathbf{c}$ were determined at full $\mathrm{Ca}^{2+}$ activation ( $\mathrm{pCa} 4.5$ ). The rate constant of the force rise upon rapid decrease of $\left[\mathrm{P}_{\mathrm{i}}\right], k_{-\mathrm{Pi}}$ is indicated by filled diamonds (red in online version). The rate constant of mechanically-induced force redevelopment, $k_{\mathrm{TR}}$ is indicated by open diamonds. The rate constant of the major force decay upon rapid increase of $\left[\mathrm{P}_{\mathrm{i}}\right]$ that refers to the rate constant of the total force decay in fs-mf $\left(k_{+\mathrm{Pi}}\right.$ in a) and to the rate constant of the second, major phase of force decay in c-mf $\left(k_{+\mathrm{Pi}(2)}\right.$ in $\left.\mathbf{c}\right)$ is indicated by dotted circles. For an illustration of the bi-phasic force decay in c-mf, see Fig. $2 \mathrm{i}$. Note the similar $\left[\mathrm{P}_{\mathrm{i}}\right]$ relations of $k_{\mathrm{TR}}$ and $k_{\mathrm{Pi}}$ and their difference to $k_{+\mathrm{Pi}}$ or $k_{+\mathrm{Pi}(2)} . \mathbf{b}, \mathbf{d}\left[\mathrm{P}_{\mathrm{i}}\right]$-dependences of parameters obtained in model simulations matched to the fs-mf and c-mf experiments in a and $\mathrm{c}$, respectively. For each myofibril experiment, four model versions differing in the sequence of the rate-limiting transition ' $f$ ' (R), the force-generating step $(\mathrm{F})$ and $\mathrm{P}_{\mathrm{i}}$ release step $(\mathrm{P})$ (models: $\mathrm{R} \rightarrow \mathrm{F} \rightarrow \mathrm{P}$, $\mathrm{R} \rightarrow \mathrm{P} \rightarrow \mathrm{F}, \mathrm{P}=\mathrm{R} \rightarrow \mathrm{F}, \mathrm{P}=\mathrm{R}=\mathrm{F}$ ) were tested for their ability to reproduce the observed $\left[\mathrm{P}_{\mathrm{i}}\right]$-dependence of $k_{\mathrm{TR}}$ and $k_{-\mathrm{Pi}}$. Model simulations indicated by $\mathrm{R} \rightarrow \mathrm{F} \rightarrow \mathrm{P}$ (relations marked by triangles with tips $u p$ ) in $\mathbf{b}$ and $\mathbf{d}$ refers to the six-step model depicted in Fig. 1b, i.e. the sequence $\mathrm{R}, \mathrm{F}$ and $\mathrm{P}$ with fast force-generation before fast $\mathrm{P}_{\mathrm{i}}$-release. In this model, the first force-generating state is an ADP.P $P_{i}$-state after step 4. Intrinsic rate constants used for $\mathrm{R} \rightarrow \mathrm{F} \rightarrow \mathrm{P}$ model: Step 1 (ATP-binding): $k_{+1}=220 \mathrm{~s}^{1}$ (fs-mf), $200 \mathrm{~s}^{-1}$ (c-mf); step 2 (ATP hydrolysis): $k_{+2}=15 \mathrm{~s}^{-1}$ (fs-mf), $10 \mathrm{~s}^{-1}$ (c-mf); $k_{-2}=1.2 \mathrm{~s}^{-1}$ (fs-mf), $2 \mathrm{~s}^{-1}$ (c-mf); step $3(\mathrm{R}): k_{+3}\left({ }^{\prime} f^{\prime}\right)=1.6 \mathrm{~s}^{-1}$ (fs-mf), $1.0 \mathrm{~s}^{-1}$ (c-mf); $k_{3}$ $\left(' f^{-}\right)=1.6 \mathrm{~s}^{-1}$ (fs-mf), $1.0 \mathrm{~s}^{-1}$ (c-mf); step $4(\mathrm{~F}): k_{+4}=16 \mathrm{~s}^{-1}$ (fs$\mathrm{mf}), 10 \mathrm{~s}^{-1}$ (c-mf); $k_{-4}=16 \mathrm{~s}^{-1}$ (fs-mf), $10 \mathrm{~s}^{-1}$ (c-mf); step 5 (P): $k_{+5}\left(\mathrm{P}_{\mathrm{i}}\right.$ release $)=16 \mathrm{~s}^{-1}(\mathrm{fs}-\mathrm{mf}), 10 \mathrm{~s}^{-1}(\mathrm{c}-\mathrm{mf}) ; k_{-5}\left(\mathrm{P}_{\mathrm{i}}\right.$ rebinding $)=9$ $\mathrm{mM}^{1} \mathrm{~s}^{1}$ (fs-mf), $1 \mathrm{mM}^{-1} \mathrm{~s}^{-1}$ (c-mf); step 6 (ADP release) $k_{+6}(g$ at isometric contraction $)=0.5 \mathrm{~s}^{-1}(\mathrm{fs}-\mathrm{mf}$ and $\mathrm{c}-\mathrm{mf}), k_{+6}(g$ at unloaded contraction $)=50 \mathrm{~s}^{-1}$ (fs-mf and c-mf). To simulate $k_{\mathrm{TR}}$-measurements (open symbols), $\left[\mathrm{P}_{\mathrm{i}}\right]$ was kept constant and $g$ switched from unloaded $\left(k_{+6}^{\prime}\right)$ to isometric contraction $\left(k_{+6}\right)$. To simulate $k_{-\mathrm{Pi}^{-}}$-measurements (filled symbols, red coloured in online version), $k_{+6}$ was kept isometric $\left(0.5 \mathrm{~s}^{-1}\right)$, and $\left[\mathrm{P}_{\mathrm{i}}\right]$ switched from $10 \mathrm{mM} \mathrm{P} \mathrm{P}_{\mathrm{i}}$ (fs-mf) or $20 \mathrm{mM}$ $\mathrm{P}_{\mathrm{i}}(\mathrm{c}-\mathrm{mf})$ to the indicated $\left[\mathrm{P}_{\mathrm{i}}\right]$. To simulate a model with sequence $\mathrm{R} \rightarrow \mathrm{P} \rightarrow \mathrm{F}$ and fast force-generation after fast $\mathrm{P}_{\mathrm{i}}$ release (relations marked by triangles with tips down), the rate constants of $\mathrm{R} \rightarrow \mathrm{F} \rightarrow \mathrm{P}$ model were kept but the sequence of $\mathrm{F}$ and $\mathrm{P}$ was interchanged. Thus, in $\mathrm{R} \rightarrow \mathrm{P} \rightarrow \mathrm{F}$ model, step $4=\mathrm{P}$, step $5=\mathrm{F}$ and the first forcegenerating state is an ADP-state. The model $(\mathrm{P}=\mathrm{R}) \rightarrow \mathrm{F}$ (relations marked by squares) presents simulations for rate-limiting $P_{i}$ release and subsequent fast force-generation: step $3(\mathrm{R})$ and step $4(\mathrm{P})$ of the $\mathrm{R} \rightarrow \mathrm{P} \rightarrow \mathrm{F}$ model were merged to a single, slow step with the forward rate constant $k_{+(4=3)}=1.6 \mathrm{~s}^{-1}$ (fs-mf) or $1.0 \mathrm{~s}^{-1}$ (c-mf) and the reverse rate constant $k_{-(4=3)}=0.9 \mathrm{mM}^{-1} \mathrm{~s}^{-1}$ (fs-mf) or $0.1 \mathrm{mM}^{-1} \mathrm{~s}^{-1}$ (c-mf). For model simulations indicated by $\mathrm{P}=\mathrm{R}=\mathrm{F}$ (relations marked by circles), $P_{i}$ release, force-generating and rate-limiting step, i.e., all steps 46 in the $\mathrm{R} \rightarrow \mathrm{F} \rightarrow \mathrm{P}$ model are merged to a single, slow step with forward rate constant $\left[k_{+(3=4=5)}\right]=1.6 \mathrm{~s}^{-1}$ (fs-mf) or $1.0 \mathrm{~s}^{-1}$ (c-mf), and reverse rate constant $\left[k_{-(3=4=5)}\right]=0.9 \mathrm{mM}^{-1} \mathrm{~s}^{-1}$ (fs-mf) or $0.1 \mathrm{mM}^{-1} \mathrm{~s}^{-1}$ (c-mf). (Color figure online)

not be always 'dissected' from the slower rate-limiting transitions reflected by $f$ as this difference was clearly temperature dependent and almost disappeared at $10{ }^{\circ} \mathrm{C}$ (Millar and Homsher 1992). As highlighted in the following chapters, the sequence and mechanistic relation of the three events is a still controversially discussed unsolved problem.
Re-exploration of the force-generating mechanism coupled to $P_{i}$ release in myofibrils

At the end of the 1990s, an important advancement for the study of the non-steady-state effects of $\left[\mathrm{P}_{\mathrm{i}}\right]$ on force kinetics came from mechanical measurements in striated muscle myofibrils which are in rapid diffusional equilibrium with the bathing medium and suitable for mechanical measurements (Colomo et al. 1997, 1998). With single or thin bundles of myofibrils (1-3 $\mu \mathrm{m}$ wide), concentrations inside the myofilament lattice can be rapidly and precisely modified without the use of caged compounds but simply by rapid alternation of perfusion fluxes. This made it possible to resolve the kinetics of isometric force rise and relaxation in calcium activation cycles as well as the kinetics of force transients initiated by $P_{i}$ jumps (Tesi et al. 2000). A real advantage of myofibril $\mathrm{P}_{\mathrm{i}}$ jumps over caged- $\mathrm{P}_{\mathrm{i}}$ skinned fibre experiments is the ability to precisely change $\left[\mathrm{P}_{\mathrm{i}}\right]$ in a much wider and controlled range and observe not only the decrease in force following sudden $\left[\mathrm{P}_{\mathrm{i}}\right]$ increase but also the reverse, i.e., force increase following sudden $\left[\mathrm{P}_{\mathrm{i}}\right]$ decrease. When submitted to rapid jumps in $\left[\mathrm{P}_{\mathrm{i}}\right]$, single or thin bundles of rabbit psoas myofibrils $\left(5^{\circ} \mathrm{C}\right.$; Fig. $2 \mathrm{a}$, c) responded with sudden changes in force and the kinetics of both the force decrease which followed the increase in $\left[\mathrm{P}_{\mathrm{i}}\right]$ (rate constant $k_{+\mathrm{Pi}}$ ) and of the force increase following the decrease in $\left[\mathrm{P}_{\mathrm{i}}\right]$ (rate constant $k_{-\mathrm{Pi}}$ ) were measured.

As previously observed in skinned fibres with caged- $\mathrm{P}_{\mathrm{i}}$, $k_{+\mathrm{Pi}}$ was scarcely affected by the activation level and about three times faster than the rate of $\mathrm{Ca}^{2+}$-induced force development $k_{\mathrm{ACT}}$, or mechanically-induced redevelopment $k_{\mathrm{TR}}$, measured at the same final $\left[\mathrm{P}_{\mathrm{i}}\right]$. Taking in account differences in experimental temperature, absolute values of $k_{+\mathrm{Pi}}$ were similar to those previously observed in caged- $\mathrm{P}_{\mathrm{i}}$ force transients in skinned fibres but the dependence on final $\left[\mathrm{P}_{\mathrm{i}}\right]$ showed no sign of saturation in the range of measurements, as expected from a two-step mechanism. Anyway, based on the close correspondence with caged- $\mathrm{P}_{\mathrm{i}}$ findings (estimated second order binding constant) and on the steady-state effect of $\left[\mathrm{P}_{\mathrm{i}}\right]$ on isometric force, showing a definite plateau at high $\left[\mathrm{P}_{\mathrm{i}}\right]$ (Tesi et al. 2002a), authors favoured cross-bridge models in which force is produced by an isomerization of AM.ADP.P ${ }_{\mathrm{i}}$ complex immediately preceding a fast and nonrate-limiting $\mathrm{P}_{\mathrm{i}}$ release step. Unexpectedly from a two-step mechanism of force-generation and $\mathrm{P}_{\mathrm{i}}$ release like depicted in Fig. 1b, rabbit psoas myofibril experiments reported that the force increase following the reversal of the jump was slower, i.e., its rate constant $k_{-\mathrm{Pi}}$ was much less than $k_{+\mathrm{Pi}}$, whereas $k_{-\mathrm{Pi}}$ was undistinguishable from $k_{\mathrm{TR}}$ measured at the same final $\left[\mathrm{P}_{\mathrm{i}}\right]$ (Figs. 2a, c, 3a; Table 1, Tesi et al. 2000). Both $k_{-\mathrm{Pi}}$ and $k_{\mathrm{TR}}$ have not only the same values but also the same calcium, $\left[\mathrm{P}_{\mathrm{i}}\right]$ and temperature dependencies, which are 
Table 1 Kinetics of $\mathrm{P}_{\mathrm{i}}$ jumps, force redevelopment and relaxation in different myofibril preparations at contaminant $(0.2 \mathrm{mM})$ and 2-5 mM $\left[\mathrm{P}_{\mathrm{i}}\right]$ in full activation solution ( $\mathrm{pCa} 4.5$ )

\begin{tabular}{|c|c|c|c|c|c|c|}
\hline \multirow[t]{2}{*}{ Myofibril type conditions } & \multirow{2}{*}{$\begin{array}{l}\text { Force generation } \\
k_{\mathrm{TR}}\left(\mathrm{s}^{-1}\right)\end{array}$} & \multirow{2}{*}{$\begin{array}{l}\mathrm{P}_{\mathrm{i}} \text { jump (-) } \\
k_{-\mathrm{Pi}}\left(\mathrm{s}^{-1}\right)\end{array}$} & \multicolumn{2}{|l|}{ Relaxation } & \multicolumn{2}{|l|}{$\mathrm{P}_{\mathrm{i}}$ jump (+) } \\
\hline & & & Slow $k_{\mathrm{REL}}\left(\mathrm{s}^{-1}\right)$ & Fast $k_{\mathrm{REL}}\left(\mathrm{s}^{-1}\right)$ & $k_{+\mathrm{Pi}(1)}\left(\mathrm{s}^{-1}\right)$ & $k_{+\mathrm{Pi}}$ or $k_{+\mathrm{Pi}(2)}\left(\mathrm{s}^{-1}\right)$ \\
\hline $\begin{array}{l}\text { Rabbit psoas } \\
0.2 \mathrm{mM} \mathrm{P}_{\mathrm{i}}\left(5^{\circ} \mathrm{C}\right)\end{array}$ & $\begin{array}{l}2.7 \pm 0.1 \\
(25)^{\mathrm{a}}\end{array}$ & $\begin{array}{l}1.7 \pm 0.1 \\
(5)^{\mathrm{f}}\end{array}$ & $\begin{array}{l}0.6 \pm 0.03 \\
(51)^{\mathrm{a}}\end{array}$ & $\begin{array}{l}17.7 \pm 1.1 \\
(51)^{\mathrm{a}}\end{array}$ & n.d. & n.d. \\
\hline $\begin{array}{l}\text { Rabbit psoas } \\
5 \mathrm{mM} \mathrm{P} \mathrm{P}_{\mathrm{i}}\left(5^{\circ} \mathrm{C}\right)\end{array}$ & $\begin{array}{l}5.4 \pm 0.6 \\
(13)^{\mathrm{b}}\end{array}$ & $\begin{array}{l}5.2 \pm 0.7 \\
(13)^{\mathrm{b}}\end{array}$ & $\begin{array}{l}3.4 \pm 0.36 \\
(15)^{\mathrm{a}}\end{array}$ & $\begin{array}{l}13.9 \pm 1.4 \\
(15)^{\mathrm{a}}\end{array}$ & n.d. & $\begin{array}{l}18.2 \pm 2.0 \\
(13)^{\mathrm{b}}\end{array}$ \\
\hline $\begin{array}{l}\text { Rabbit soleus } \\
0.2 \mathrm{mM} \mathrm{P}_{\mathrm{i}}\left(15^{\circ} \mathrm{C}\right)\end{array}$ & $\begin{array}{l}2.1 \pm 0.3 \\
(12)^{\mathrm{a}}\end{array}$ & n.d. & $\begin{array}{l}0.3 \pm 0.04 \\
(13)^{\mathrm{a}}\end{array}$ & $\begin{array}{l}2.1 \pm 0.2 \\
(13)^{\mathrm{a}}\end{array}$ & n.d. & n.d. \\
\hline $\begin{array}{l}\text { Rabbit soleus } \\
2 \mathrm{mM} \mathrm{P}_{\mathrm{i}}\left(15^{\circ} \mathrm{C}\right)\end{array}$ & $\begin{array}{l}1.8 \pm 0.2 \\
(6)^{\mathrm{b}}\end{array}$ & $\begin{array}{l}1.8 \pm 0.2 \\
(6)^{\mathrm{b}}\end{array}$ & $\begin{array}{l}0.8 \pm 0.1 \\
(8)^{\mathrm{c}}\end{array}$ & $\begin{array}{l}5.8 \pm 0.5 \\
(8)^{\mathrm{c}}\end{array}$ & n.d. & $\begin{array}{l}3.2 \pm 0.2 \\
(6)^{\mathrm{b}}\end{array}$ \\
\hline $\begin{array}{l}\text { Guinea pig, cardiac } \\
0.2 \mathrm{mM} \mathrm{P}_{\mathrm{i}}\left(10^{\circ} \mathrm{C}\right)\end{array}$ & $\begin{array}{l}1.3 \pm 0.2 \\
(9)^{\mathrm{d}}\end{array}$ & $\begin{array}{l}1.4 \pm 0.1 \\
(9)^{\mathrm{d}}\end{array}$ & $\begin{array}{l}0.7 \pm 0.1 \\
(32)^{\mathrm{e}}\end{array}$ & $\begin{array}{l}10.9 \pm 0.4 \\
(32)^{\mathrm{e}}\end{array}$ & n.d. & n.d. \\
\hline $\begin{array}{l}\text { Guinea pig, cardiac } \\
5 \mathrm{mM} \mathrm{P}_{\mathrm{i}}\left(10^{\circ} \mathrm{C}\right)\end{array}$ & $\begin{array}{l}1.9 \pm 0.2 \\
(9)^{\mathrm{d}}\end{array}$ & $\begin{array}{l}1.8 \pm 0.1 \\
(9)^{\mathrm{d}}\end{array}$ & $\begin{array}{l}1.9 \pm 0.5 \\
(7)^{\mathrm{e}}\end{array}$ & $\begin{array}{l}18.7 \pm 2.3 \\
(7)^{\mathrm{e}}\end{array}$ & $\begin{array}{l}1.8 \pm 0.2 \\
(6)^{\mathrm{d}}\end{array}$ & $\begin{array}{l}7.4 \pm 0.9 \\
(6)^{\mathrm{d}}\end{array}$ \\
\hline
\end{tabular}

Mean \pm SEM, number in parentheses $=n$

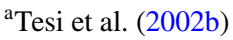

b'Tesi et al. (2000)

${ }^{\mathrm{c}}$ Belus et al. (2003)

${ }^{\mathrm{d}}$ Stehle (2017)

${ }^{\mathrm{e}}$ Stehle et al. (2002a)

${ }^{\mathrm{f}}$ Unpublished

different from those of $k_{+\mathrm{Pi}}$ (Tesi et al. 2000; Piroddi et al. 2003).

The interpretation of the unexpected marked asymmetry of the rate of force change when a given final $\left[\mathrm{P}_{\mathrm{i}}\right]$ is approached from a higher versus a lower $\left[\mathrm{P}_{\mathrm{i}}\right]$ posed then a serious problem of interpretation. Poggesi, Tesi and coworkers (Tesi et al. 2000, 2002a) tested the possible role of experimental systematic artifacts, mainly due to lack of control of mechanical conditions of myofibrils during contraction, but results of ADP or $\mathrm{Ca}^{2+}$ jumps showed that the asymmetry in the kinetics of declining or rising force transients was present only in $P_{i}$ jumps. At the same time, attempts to fit this behavior with current models of cross-bridge action failed (Smith and Sleep 2006). An interesting point came from experiments performed with rabbit soleus myofibrils which confirmed the close correspondence of the kinetics of the transient rise in force initiated by a sudden decrease in $\left[\mathrm{P}_{\mathrm{i}}\right]$ and $k_{\mathrm{TR}}$ but reported the asymmetry in force kinetics following $\mathrm{P}_{\mathrm{i}}$ jumps in opposite directions only at $20^{\circ} \mathrm{C}$. At $15^{\circ} \mathrm{C}$, the difference between $k_{+\mathrm{Pi}}, k_{-\mathrm{Pi}}$ and $k_{\mathrm{TR}}$ were greatly reduced and in some cases all the rates superimposed on $k_{\mathrm{TR}}$, as shown in Fig. 2d-f. This observation is in line with previous results from caged- $\mathrm{P}_{\mathrm{i}}$ experiment in soleus muscle, reporting a marked temperature dependence of $k_{+\mathrm{Pi}}$ which at $10{ }^{\circ} \mathrm{C}$ was also found almost indistinguishable from $k_{\mathrm{TR}}$ (Millar and Homsher 1992). The explanation given at the time by Homsher and coworkers was that in slow muscle, depending on temperature, "the force generating and $\mathrm{P}_{\mathrm{i}}$ release steps are not kinetically isolated from the rest of the cycle as is the case in fast twitch muscle fibres' and the $P_{i}$ release itself is part of the rate limiting step(s) of the crossbridge chemo-mechanical cycle. In conclusion, experiments in rabbit skeletal myofibrils re-opened the question about the one step/two steps coupling of $\mathrm{P}_{\mathrm{i}}$ release with force generation and the assignment of the overall rate-limiting step.

Recently, a possible resolution of the puzzle posed by the asymmetry in $P_{i}$ jumps came from the investigation of force responses and individual sarcomere dynamics upon rapid increase or decrease in $\mathrm{P}_{\mathrm{i}}$ in maximally $\mathrm{Ca}^{2+}$ activated guinea pig cardiac myofibrils (Stehle 2017). This study showed that in this experimental model $\left(10{ }^{\circ} \mathrm{C}\right)$, the force decay upon rapid increase in $\left[\mathrm{P}_{\mathrm{i}}\right]$ is clearly biphasic with an initial slow decline [phase $\left.1 ; k_{+\mathrm{Pi}(1)}\right]$ and a subsequent three to fivefold faster major decay [phase $2 ; k_{+\mathrm{Pi}(2)}$ ]. The kinetics of this major second phase corresponded to the kinetics of the major fast phase detected in both fast skeletal muscle skinned fibres and myofibrils. As previously observed in skeletal myofibrils, also here the kinetics of the rise in force following $\mathrm{P}_{\mathrm{i}}$ decrease was monophasic $\left(k_{-\mathrm{Pi}}\right)$ and had the same rate as $k_{\mathrm{TR}}$ or $k_{\mathrm{ACT}}$ at the same final ligand concentration. Interestingly, the monitoring of individual sarcomeres of 'isometrically' held myofibrils induced by $\mathrm{P}_{\mathrm{i}}$ jumps showed that sarcomere dynamics during force change was present only upon rapid increase in $\left[\mathrm{P}_{\mathrm{i}}\right]$, starting with an individual sarcomere give triggering fast phase 2 . This behavior closely matches the sarcomere dynamics taking 
place in guinea pig cardiac myofibrils during the fast phase of force relaxation following calcium removal (Stehle et al. 2002a; Telley et al. 2006), both for the absolute kinetics and $\left[\mathrm{P}_{\mathrm{i}}\right]$ dependence. Interestingly, the force kinetics of the other phases ('truly isometric') were found reasonably symmetric, with the rate constant of the initial slow decline upon rapid increase in $\left[\mathrm{P}_{\mathrm{i}}\right] k_{+\mathrm{Pi}(1)}$ as slow as $k_{-\mathrm{Pi}}$ or $k_{\mathrm{TR}}$ and dependent only on the final $\left[\mathrm{P}_{\mathrm{i}}\right]$ (Stehle 2017). These results strongly suggest that, at least in cardiac myofibrils, the asymmetry arises from sarcomere dynamics, speeding up the force decrease transient by the superimposition of a relaxationlike process (Stehle et al. 2002a; Tesi et al. 2002b; Poggesi et al. 2005). $k_{-\mathrm{Pi}}$ or $k_{\mathrm{TR}}$ would then better reflect the overall sarcomere cross-bridge kinetics and its $\left[\mathrm{P}_{\mathrm{i}}\right]$ dependence, suggesting that $P_{i}$ release cannot be separated from the ratelimiting transition leading to force-generating states in the chemo-mechanical cycle.

How then to reconcile these findings with previous $P_{i}$ jumps in skeletal muscle myofibrils and skinned fibres? The main problem is raised by fast skeletal muscle, as in slow muscle, depending on temperature, it is possible to find conditions were $\mathrm{P}_{\mathrm{i}}$ jump kinetics comes close (Millar and Homsher 1992; Tesi et al. 2000) or even superimposes to $k_{\mathrm{TR}}$ without asymmetry (Fig. 2f). In rabbit psoas myofibrils, many different tests $\left(\mathrm{Ca}^{2+}\right.$ jumps, ADP and BDM jumps; Tesi et al. 2000) were employed to rule out the possibility that mechanical artifacts and sarcomere dynamics could be the origin of the marked asymmetry of the rate of force changes when a given final $\left[\mathrm{P}_{\mathrm{i}}\right]$ is approached from a higher versus a lower $\left[\mathrm{P}_{\mathrm{i}}\right]$. Results of these experiments showed that the asymmetry in the kinetics of rising or declining force transients was present only in $\mathrm{P}_{\mathrm{i}}$ jumps. Moreover, a relaxation-like behavior in $\mathrm{P}_{\mathrm{i}}$ jumps to final increased $\left[\mathrm{P}_{\mathrm{i}}\right]$ was excluded mainly based: (1) on the lack of effect of initial $\left[\mathrm{P}_{\mathrm{i}}\right]$ and force on the kinetics of $\mathrm{P}_{\mathrm{i}}$ jumps, and (2) on the strong $\mathrm{P}_{\mathrm{i}}$ dependence of $k_{+\mathrm{Pi}}$ versus an almost $\mathrm{P}_{\mathrm{i}}$ insensitive fast phase relaxation in psoas muscle at $5{ }^{\circ} \mathrm{C}$ (Tesi et al. 2002b) and Table 1. Unfortunately, the resolution of $\mathrm{P}_{\mathrm{i}}$ jumps experiments in rabbit psoas myofibrils at low temperature was limited by a substantial mechanical artifact on pipette movement that together with the dead time of solution change could have masked or blurred the possible presence of an initial linear phase of relaxation. However, in this case the delay is expected to last much longer than the mechanical artifact of about $80-90 \mathrm{msec}$ at $5 \mathrm{mM}$ final $\left[\mathrm{P}_{\mathrm{i}}\right]$ (Tesi et al. 2002b) and Table 1.

Does in rabbit psoas myofibrils the apparent monophasic behavior of $k_{+\mathrm{Pi}}$, its 3-4 times higher value than $k_{\mathrm{TR}}$ at maximally activating $\left[\mathrm{Ca}^{2+}\right]$ and its high $\left[\mathrm{P}_{\mathrm{i}}\right]$ dependence arise by switching from isometric $\mathrm{P}_{\mathrm{i}}$ jumps of small amplitude (low $\left.\left[\mathrm{P}_{\mathrm{i}}\right]\right)$ to conditions progressively dominated by relaxationlike behaviour and fast $k_{\mathrm{REL}}$ (high $\left.\left[\mathrm{P}_{\mathrm{i}}\right]\right)$ ? Should this happen, then $\mathrm{P}_{\mathrm{i}}$ release step would match the rate-limiting transition $f$ of cross-bridge cycle assayed by $k_{\mathrm{TR}}$. But another possibility is that depending on experimental model (fast or slow muscle) or conditions ([ $\left.\mathrm{P}_{\mathrm{i}}\right]$, temperature, initial force), the applied perturbation probes an event, i.e. $\mathrm{P}_{\mathrm{i}}$ release step or $P_{i}$ release associated step, that is (or is not) rate-limiting for the overall cross-bridge cycle. If the latter is the case, then it needs to be determined which mechanism other than sarcomere dynamics can explain the asymmetry of $k_{+\mathrm{Pi}}$ and $k_{-\mathrm{Pi}}$, and why $k_{-\mathrm{Pi}}$ is similar to $k_{\mathrm{TR}}$. These questions remain open and further experiments are needed to asses these points, combining force and sarcomere dynamics measurements during $P_{i}$ jumps in fast skeletal myofibrils.

\section{Comparison of force kinetics and sarcomere dynamics upon changes in $\left[\mathrm{P}_{\mathrm{i}}\right]$ and $\left[\mathrm{Ca}^{2+}\right]$}

In myofibril preparations from fast skeletal, slow skeletal, and cardiac muscles, rapid decreases in $\left[\mathrm{P}_{\mathrm{i}}\right]$ and rapid increases in $\left[\mathrm{Ca}^{2+}\right]$ induce mono-phasic slow force rises (Tesi et al. 2000, 2002a; Stehle 2017). While the force decay during full relaxation induced by complete $\mathrm{Ca}^{2+}$ removal is clearly biphasic in all these myofibril preparations (Poggesi et al. 2005), the biphasic behaviour of force decay after the increase in $\left[\mathrm{P}_{\mathrm{i}}\right]$ is only clearly seen in cardiac myofibrils (Stehle 2017) and remains uncertain for skeletal myofibrils (Fig. 2). In cardiac myofibrils there is a strikingly similar pattern of sarcomere dynamics occurring during the second, fast phases of force decays upon rapid increase of $\left[\mathrm{P}_{\mathrm{i}}\right]$ and rapid decrease of $\left[\mathrm{Ca}^{2+}\right]$ (Stehle et al. 2002a; Stehle 2017). Cardiac myofibrils from guinea pig are a preferential preparation to resolve the spatial-temporal behaviour of sarcomere dynamics because of the slow myosin isoform and the discrete length change behaviour of individual sarcomeres. In both situations, upon increase of $\left[\mathrm{P}_{\mathrm{i}}\right]$ and upon decrease of $\left[\mathrm{Ca}^{2+}\right]$, the transition from the slow first phase to the fast second phase in the biphasic force decay coincides with the onset of rapid lengthening, i.e., with the onset of 'give', of a single, weak sarcomere, whereupon the give propagates from one sarcomere to the next along the myofibril. As discussed below, besides some differences arising from inactivation of cross-bridge attachment after $\mathrm{Ca}^{2+}$ removal and load dependence of sarcomere dynamics, the corresponding phases in $\mathrm{P}_{\mathrm{i}}$ jump and relaxation experiments observed in cardiac myofibrils (Stehle et al. 2002a; Stehle 2017) are based on similar rates in the cross-bridge cycle.

\section{Similarities of force rises upon $\left[\mathrm{P}_{\mathrm{i}}\right]$ and $\left[\mathrm{Ca}^{2+}\right]$ changes and their implications}

As indicated by their similar rate constants, force rises induced by decrease in $\left[\mathrm{P}_{\mathrm{i}}\right]\left(k_{-\mathrm{Pi}}\right)$, increase in $\left[\mathrm{Ca}^{2+}\right]\left(k_{\mathrm{ACT}}\right)$ and slack-restretch $\left(k_{\mathrm{TR}}\right)$ occur with very similar kinetics 
determined by the transitions in the cycle limiting redistribution of cross-bridges among non-force and force-generating states (Figs. 2, 3), (Stehle et al. 2009; Stehle 2017). Thus, all these force rises primarily reflect cross-bridge turnover kinetics and even the force rise in $k_{\mathrm{ACT}}$-measurements seems to be little further limited by the additional $\mathrm{Ca}^{2+}$ activation of the thin filament in comparison to $k_{\mathrm{TR}}$-measurements, a common finding in myofibrils and fibres from skeletal and cardiac muscles (Wahr and Rall 1997; Palmer and Kentish 1998; Stehle et al. 2002a, b; Tesi et al. 2002a, b), and consistent with $\mathrm{Ca}^{2+}$ rapidly switching on troponin in skeletal and cardiac myofibrils (Solzin et al. 2007; Lopez-Davila et al. 2012). The observed rate constants of all three type of force rise reflect the sum of apparent rate constants of crossbridge turnover from non-force-generating to force-generating states $\left(f_{\text {app }}\right)$ and from force-generating to non-force states via backwards $\left(f_{\text {app }}^{-}\right)$and forwards $\left(g_{\text {app }}\right)$ cycling, respectively. $f_{\text {app }}$ increases with increasing $\left[\mathrm{Ca}^{2+}\right], f_{\text {app }}^{-}$increases with stretch and increasing $\left[\mathrm{P}_{\mathrm{i}}\right]$, while $g_{\text {app }}$ mainly increases with lowering the load and increasing shortening velocity. In the absence of sarcomere dynamics, $k_{\text {obs }}=$ $f_{\text {app }}\left(\left[\mathrm{Ca}^{2+}\right]\right)+f_{\text {app }}^{-}\left(\left[\mathrm{P}_{\mathrm{i}}\right]\right)+g_{\text {app }}$, where $k_{\text {obs }}$ can be $k_{-\mathrm{Pi}}, k_{\mathrm{TR}}$ or $k_{\mathrm{ACT}}$, and $f_{\text {app }}, f_{\text {app }}^{-}$and $g_{\text {app }}$ adopt values near the isometric contraction condition. Under this condition, both $f_{\text {app }}^{-}\left(\left[\mathrm{P}_{\mathrm{i}}\right]\right)$ and $g_{\text {app }}$ approach low values, leading to slow turnover of cross-bridges out of force-generating states and a high duty ratio $\left(f_{\text {app }} /\left(f_{\text {app }}+f_{\text {app }}^{-}+g_{\text {app }}\right)\right)$.

\section{Differences of force decay upon $\left[\mathrm{P}_{\mathrm{i}}\right]$ and $\left[\mathrm{Ca}^{2+}\right]$ changes and their implications}

The kinetics of the initial, slow force decay following rapid $\mathrm{Ca}^{2+}$ removal is consistent with a rapid switch-off of the regulatory troponin-tropomyosin system, rapidly preventing de novo formation of force-generating crossbridges (Stehle et al. 2002a; Tesi et al. 2002b; Poggesi et al. 2005). Because $f_{\text {app }}$ rapidly decreases close to zero, the rate constant of the initial, linear slow relaxation phase, slow $k_{\mathrm{REL}}$, during which sarcomeres and half-sarcomeres remain isometric (Stehle et al. 2002a; Telley et al. 2006), reflects $f_{\text {app }}^{-}\left(\left[\mathrm{P}_{\mathrm{i}}\right]\right)+g_{\text {app }}$. This is different to the rate constant $k_{+\mathrm{Pi}(1)}$ of the initial slow force decay following rapid increase of $\left[\mathrm{P}_{\mathrm{i}}\right]$ observed in cardiac myofibrils, where $\left[\mathrm{Ca}^{2+}\right]$ remains constantly high and $f_{\text {app }}$ maintains at the former value. Thus, $k_{+\mathrm{Pi}(1)}$ like $k_{-\mathrm{Pi}}$ reflects $f_{\text {app }}+f$ ${ }_{\text {app }}\left(\left[\mathrm{P}_{\mathrm{i}}\right]\right)+g_{\text {app }}$. Because only $f_{\text {app }}^{-}$but not $f_{\text {app }}$ changes with the $\left[\mathrm{P}_{\mathrm{i}}\right]$, the dependences of $k_{-\mathrm{Pi}}$ and $k_{+\mathrm{Pi}(1)}$ versus the $\left[\mathrm{P}_{\mathrm{i}}\right]$ reveals the function $f_{\text {app }}\left(\left[\mathrm{P}_{\mathrm{i}}\right]\right) k_{-\mathrm{Pi}}$ increases linearly with $\left[\mathrm{P}_{\mathrm{i}}\right]$, at rates of $0.9 \mathrm{~s}^{1}$ per $\mathrm{mM} \mathrm{P}_{\mathrm{i}}$ in fast skeletal myofibrils and $0.1 \mathrm{~s}^{1}$ per $\mathrm{mM} \mathrm{P}_{\mathrm{i}}$ in cardiac myofibrils (Tesi et al.
2000; Stehle 2017) (Fig. 3a, c). Linear $\left[\mathrm{P}_{\mathrm{i}}\right]$-dependences are also observed for $k_{+\mathrm{Pi}(1)}$ in cardiac myofibrils (Stehle 2017) and $k_{+\mathrm{Pi}}$ in slow skeletal myofibrils, especially at low temperature (Tesi et al. 2000). This suggests that $f_{\text {app }}$ increases in proportion to $\left[\mathrm{P}_{\mathrm{i}}\right]$, i.e., $f_{\text {app }}^{-}\left(\cdot\left[\mathrm{P}_{\mathrm{i}}\right]\right)=$ const $\cdot\left[\mathrm{P}_{\mathrm{i}}\right]$.

Such a linear function is expected with force reduction induced by $\mathrm{P}_{\mathrm{i}}$ rebinding being coupled to a rate-limiting transition in the cross-bridge cycle as seen by the simulated relations between $k_{-\mathrm{Pi}}$ and $\left[\mathrm{P}_{\mathrm{i}}\right]$ for the models termed $\mathrm{P}=\mathrm{R}=\mathrm{F}$ and $(\mathrm{P}=\mathrm{R}) \rightarrow \mathrm{F}$ described in Fig. 3b, $\mathrm{d}$.

In cardiac myofibrils, the values of $f_{\text {app }}^{-}$and $g_{\text {app }}$ dramatically increase with the onset of sarcomere give and the beginning of the second major fast phase of force decays during relaxation or upon the increase of $\left[\mathrm{P}_{\mathrm{i}}\right]$ reflected by the high values of their rate constants fast $k_{\mathrm{REL}}$ and $k_{+\mathrm{Pi}(2)}$, respectively (Stehle et al. 2002a; Stehle 2017). Because $k_{+\mathrm{Pi}(2)}$ correlates with the propagation rate of sarcomere give and $k_{+\mathrm{Pi}(2)}$ decreases when the amplitude of the force change is reduced by switching from different initial $\left[\mathrm{P}_{\mathrm{i}}\right]$ to the same final $\left[\mathrm{P}_{\mathrm{i}}\right]$, the rate of cross-bridge detachment during sarcomere give is likely affected by the amplitude of the force change. The latter could also explain why in cardiac myofibrils $k_{+\mathrm{Pi}(2)}$ is lower than fast $k_{\mathrm{REL}}$ measured at same $\left[\mathrm{P}_{\mathrm{i}}\right]$, because relaxation from full activation causes a large force decay. From a mechanistic point of view, sarcomere give during relaxation and upon $\mathrm{P}_{\mathrm{i}}$ jump can both be explained by give stretching crossbridges and accelerating cross-bridge detachment via faster backwards cycling, i.e., by increasing $f_{\text {app }}^{-}$. This view is supported by the findings in fibre studies that stretch rapidly reduces the rate of $\mathrm{P}_{\mathrm{i}}$ release, inducing redistribution of cross-bridges towards ADP. $\mathrm{P}_{\mathrm{i}}$-binding states (Mansfield et al. 2012). The fast cross-bridge detachment in the lengthening (give) sarcomeres reduces the load in the serially connected other sarcomeres and therein promotes cross-bridge detachment via fast forwards cycling by increasing $g_{\text {app }}$ (Stehle et al. 2009). Furthermore, temporal and spatial sequence of give is directed by compliance of serial and transversal structures that connect the cross-bridge registers of the half-sarcomeres (Telley and Denoth 2007; Campbell 2016).

One difference in sarcomere dynamics during relaxation after $\mathrm{Ca}^{2+}$ removal and sarcomere dynamics increase of $\left[\mathrm{P}_{\mathrm{i}}\right]$ is the shortening of sarcomeres before their give. In complete relaxations, sarcomere shortening is very small (Poggesi et al. 2005) and amounts in average to less than $5 \mathrm{~nm}$ per half sarcomere (Telley et al. 2006). Negligible sarcomere shortening during relaxation indicates that cross-bridges cannot reform new interactions due to rapid inactivation upon $\mathrm{Ca}^{2+}$ removal and cannot drive filament sliding beyond a critical distance limited by the 
interactions existing at $\mathrm{Ca}^{2+}$ removal. Because the myofibril is fixed at its ends and overall length remains almost constant, the lengthening of sarcomere give during relaxation is mainly balanced by shortening of passive compliant sarcomeres at the ends while the inner segment lengthens (Telley et al. 2006). In contrast, after a $P_{i}$ jump, crossbridges can still reform continuously force-generating interactions and sarcomeres actively shorten by $\sim 100 \mathrm{~nm}$ before give spreads to them (see Fig. 3a in Stehle 2017). In this case, give of individual sarcomeres is almost fully balanced by shortening of the $\mathrm{Ca}^{2+}$-activated sarcomeres in the inner segment, which hardly changes in total and mean sarcomere length. This explains why no sarcomere dynamics has been detected by measurement of mean sarcomere length in $\mathrm{P}_{\mathrm{i}}$ jump experiments (Dantzig et al. 1992), whereas the role of sarcomere give for initiating rapid relaxation has been early recognized (Edman and Flitney 1982).

\section{Significance of slow force response upon $\left[P_{i}\right]$ decrease for the cross-bridge mechanism}

The fundamental role of the $\mathrm{P}_{\mathrm{i}}$ release for limiting the rate of contraction becomes very evident, when the kinetics of a force rise induced by a rapid decrease of $\left[\mathrm{P}_{\mathrm{i}}\right]$ (rate constant $\left.k_{-\mathrm{Pi}}\right)$ is compared with the de novo force generation induced by a rapid increase of $\left[\mathrm{Ca}^{2+}\right]$ (rate constant $k_{\mathrm{ACT}}$ ) or a large mechanical perturbation (rate constant $k_{\mathrm{TR}}$ ). Force rises induced by $\left[\mathrm{P}_{\mathrm{i}}\right]$-decreases and $\left[\mathrm{Ca}^{2+}\right]$-increases are monophasic exponential and exhibit the same kinetics (Tesi et al. 2000; Stehle 2017). At same final $\left[\mathrm{P}_{\mathrm{i}}\right]$ and $\left[\mathrm{Ca}^{2+}\right]$, the rate constants $k_{-\mathrm{Pi}}$ and $k_{\mathrm{TR}}$ are the same, (Fig. 3a, c; Table 1). $\mathrm{Ca}^{2+}$ induces force generation de novo from the relaxed state, requiring conformational changes for activation of the thin filament and conformational changes in the myosin head for formation of a stereospecific myosin-actin interaction. The latter $\mathrm{Ca}^{2+}$-regulated transitions in the cross-bridge cycle usually are assumed to occur before $\mathrm{P}_{\mathrm{i}}$ release and to limit the rate of force generation, whereas $P_{i}$ release and force-generating step per se are regarded to be fast events. Thus $\mathrm{P}_{\mathrm{i}}$ release/rebinding is usually considered to be a rapid equilibrium (Kawai and Halvorson 1991; Dantzig et al. 1992; Takagi et al. 2004). Aside from this there is ongoing discussion about the sequence of the $\mathrm{P}_{\mathrm{i}}$ release step and the force-generating step (Llinas et al. 2015; Muretta et al. 2015). The finding that rapid decrease of $\left[\mathrm{P}_{\mathrm{i}}\right]$ induces the same slow force rise as de novo force generation rules out sequential models of a slow rate-limiting transition preceding a fast force-generating step coupled to rapid $\mathrm{P}_{\mathrm{i}}$ release, regardless of whether first the force is generated or the $\mathrm{P}_{\mathrm{i}}$ is released (Stehle 2017). This conclusion is corroborated by the simulated $\left[\mathrm{P}_{\mathrm{i}}\right]$ dependences of $k_{-\mathrm{Pi}^{-}}$and $k_{\mathrm{TR}}$ at maximally activating $\left[\mathrm{Ca}^{2+}\right]$ for different model scenarios (Fig. 3b, d). Model scenarios involving a fast force-generating step either before or after fast $\mathrm{P}_{\mathrm{i}}$ release (models termed $\mathrm{R} \rightarrow \mathrm{F} \rightarrow \mathrm{P}$ and $\mathrm{R} \rightarrow \mathrm{P} \rightarrow \mathrm{F}$ in Fig. $3 \mathrm{~b}, \mathrm{~d}$ ) predict higher values of $k_{-\mathrm{Pi}}$ compared to $k_{\mathrm{TR}}$, in contrast with the similar values of $k_{-\mathrm{Pi}}$ and $k_{\mathrm{TR}}$ observed in fast skeletal and cardiac myofibrils experiments. Such models also fail to reproduce the strong rate modulation of $k_{\mathrm{TR}}$ by [ $\left.\mathrm{P}_{\mathrm{i}}\right]$ observed in experiments (Fig. 3a, c). Thus, uncoupling of $\mathrm{P}_{\mathrm{i}}^{\circ}$ release/rebinding from the ratelimiting forward/backwards transitions $f$ and $f^{-}$results in nearly flat relations of $k_{\mathrm{TR}}$ versus the $\left[\mathrm{P}_{\mathrm{i}}\right]$ (simulations of $\mathrm{R} \rightarrow \mathrm{F} \rightarrow \mathrm{P}$ and $\mathrm{R} \rightarrow \mathrm{P} \rightarrow \mathrm{F}$ models in Fig. 3b, d). In contrast, assigning $\mathrm{P}_{\mathrm{i}}$ release/rebinding the rate-limiting transitions $f$ and $f^{-}$(models termed $\mathrm{P}=\mathrm{R}=\mathrm{F}$ and $(\mathrm{P}=\mathrm{R}) \rightarrow \mathrm{F}$ in Fig. 3b, d) yields similar values of $k_{-\mathrm{Pi}}$ and $k_{\mathrm{TR}}$ as observed in the myofibril experiments (Fig. 3a, c). Interestingly, these models also produce two further features evident in myofibril experiments, i.e., (1) strong rate-modulation of $k_{\mathrm{TR}}$ by [P $\mathrm{P}_{\mathrm{i}}$ ], and (2) linear relation of $k_{-\mathrm{Pi}}$ versus [ $\mathrm{P}_{\mathrm{i}}$ ]. In summary the similarity of $k_{-\mathrm{Pi}}, k_{\mathrm{TR}}$ and $k_{\mathrm{ACT}}$ at maximally activating $\left[\mathrm{Ca}^{2+}\right]$, and the $\left[\mathrm{P}_{\mathrm{i}}\right]$-dependences of $k_{-\mathrm{Pi}}$ and $k_{\mathrm{TR}}$ indicate that upon perturbing the $\mathrm{P}_{\mathrm{i}}$ release $/ \mathrm{P}_{\mathrm{i}}$ binding equilibrium, the cross-bridges have to pass the same rate-limiting transition as they do when force is generated de novo, either upon large scale mechanical perturbation as well as upon $\mathrm{Ca}^{2+}$ activation. The simplest explanation for this would be that $\mathrm{P}_{\mathrm{i}}$ release/rebinding is tied to a slow, fully reversible conformational change in the cross-bridge controlled by $\mathrm{Ca}^{2+}$ activation of the thin filament.

Force kinetics upon $\left[\mathrm{P}_{\mathrm{i}}\right]$-decrease reflecting rate-limiting steps also set a new criterion for extended models that contain multiple force-generating states for straightforwardly integrating the rapid force recovery after small length change into the ATPase cycle (Caremani et al. 2013). Although the force-generating steps can occur repetitively, uncoupled, independent from $P_{i}$ release in this model, they still involve a fast isomerization step coupled to rapid $\mathrm{P}_{\mathrm{i}}$ release for priming the ability of cross-bridges to undergo these force-generating steps. Such a fast priming step still predicts faster force responses upon $\left[\mathrm{P}_{\mathrm{i}}\right]$ changes than observed in $k_{\mathrm{TR}}$-measurements. Again, to overcome this problem, the $\mathrm{P}_{\mathrm{i}}$ release must be coupled to a rate-limiting transition with slow rate $f$.

The slow force responses upon $\left[\mathrm{P}_{\mathrm{i}}\right]$ changes can be explained in either way, but each of them requires exceptional assumptions. One of them is that $\left[\mathrm{P}_{\mathrm{i}}\right]$ modulates the force per cross-bridge rather than the number of crossbridges. This relates to the idea that the energy transformation of $\mathrm{P}_{\mathrm{i}}$ release into force generation is an irreversible step whereby the $\left[\mathrm{P}_{\mathrm{i}}\right]$ determines the average force per crossbridge rather than the time a cross-bridge spends in forcegenerating states; i.e. rather than the duty ratio. This explanation is very unlikely because recent fine mechanical measurements in skinned fibres that take filament 
compliance into account showed that force per cross-bridge is little or not affected by the $\left[\mathrm{P}_{\mathrm{i}}\right]$ (Caremani et al. 2008). The rate-modulation of $k_{\mathrm{TR}}$ by [ $\mathrm{P}_{\mathrm{i}}$ ] supports the alternative explanation of high $\left[\mathrm{P}_{\mathrm{i}}\right]$ lowering the duty ratio via increasing the rate constant $f_{\text {app }}^{-}$of backwards cycling according to a twostep mass action model, i.e. by lowering the duty in proportion to $f_{\text {app }} /\left(f_{\text {app }}+f_{\text {app }}^{-}+g_{\text {app }}\right)$. High duty ratios of 0.88 (Huxley 1957) and 0.75 (Brenner 1988) are calculated from the values of $f$ and $g$ for fast skeletal muscle fibres at maximally activating $\left[\mathrm{Ca}^{2+}\right]$. Because $\mathrm{P}_{\mathrm{i}}$ is always present under physiological conditions in intact fibres and $\mathrm{P}_{\mathrm{i}}$ can accumulate in skinned fibres, the duty ratio at nominal $\mathrm{P}_{\mathrm{i}}$-free conditions like in myofibrils could be even higher than these values. However, the calculation of the duty ratio based on these simple 2-step mass action models assumes that (1) all compliance of the $\mathrm{Ca}^{2+}$ activated sarcomere resides in the crossbridge, and (2) all cross-bridges participate in cycling. Both are likely not the case because of filament compliance and geometric constraints in the sarcomere which might partly explain the lower duty ratio of 0.33 evaluated from accurate stiffness measurements at different sarcomere length (Linari et al. 2007). The effect of the 3-D lattice organisation on restricting acto-myosin binding has been recently modelled in (Mijailovich et al. 2016).

Another explanation for slow force responses upon $\left[\mathrm{P}_{\mathrm{i}}\right]$ changes would be that the $P_{i}$ release is not a classical rapid equilibrium. Structurally, $\mathrm{P}_{\mathrm{i}}$ release can be described by the backdoor release mechanism (Yount et al. 1995; Llinas et al. 2015). It has been proposed that the $P_{i}$ is not released immediately after leaving the active site and may stay for significant time in the backdoor release tunnel (Houdusse and Sweeney 2016). How the delayed backdoor release and the potential rebinding of $\mathrm{P}_{\mathrm{i}}$ to the active site would modulate force kinetics is not clear yet. However, high energy barriers for backdoor release and rebinding of $\mathrm{P}_{\mathrm{i}}$ could explain why $\mathrm{P}_{\mathrm{i}}$ release and $\mathrm{P}_{\mathrm{i}}$ binding are coupled to the rate-limiting forward step $f^{\rightarrow}$ and its reversal $f^{\Downarrow}$, respectively. Alternatively, $\mathrm{P}_{\mathrm{i}}$ release per se and $f \rightarrow$ might be rapid but $\mathrm{P}_{\mathrm{i}}$ release be still coupled to the rate-limiting transition $f$ if $\mathrm{P}_{\mathrm{i}}$ release only occurs from a very rare cross-bridge configuration or little occupied pre- $\mathrm{P}_{\mathrm{i}}$ release state $\left(A_{0}\right)$ (Geeves and Holmes 2005). In such a scenario, the likelihood (rate) of $P_{i}$ release and thus $f$ is limited by the low occupancy of $A_{0}$ because $f$ relates to the product of the forward step $f \rightarrow$ of $\mathrm{P}_{\mathrm{i}}$ release and $\left[A_{0}\right]$. If $\left[A_{0}\right]$ is low, $\mathrm{P}_{\mathrm{i}}$ release per se $\left(f^{\rightarrow}\right)$ might be fast but the rate of $\mathrm{P}_{\mathrm{i}}$ release $(f)$ still be rate-limiting.

Finally, it needs to be explained why slow force responses probed by $\left[\mathrm{P}_{\mathrm{i}}\right]$ changes kinetically differ from fast force responses probed by small length changes, the so called 'force recovery'. While cross-bridges undergo a slow structural change or adopt a rare configuration for enabling $\mathrm{P}_{\mathrm{i}}$ release and priming de novo force-generation during the ATPase cycle, force re-generation in contrast reflects a fast process uncoupled from the ATPase cycle that occurs from already primed states without need to resemble the slow structural change or adopt the rare configuration coupled to $\mathrm{P}_{\mathrm{i}}$ release (Caremani et al. 2013). Both force generating processes take place in the cross-bridge cycle. Finding the link between the two processes will be an important goal in muscle research. Complete understanding of the cross-bridge mechanism will require identification and characterization of the intermediates involved in both processes.

Taken together, the slow kinetics of force rise upon $\left[\mathrm{P}_{\mathrm{i}}\right]$ decrease in cardiac myofibril studies indicate that $P_{i}$ release is strongly coupled to the same rate-limiting transition that determines de novo force generation upon $\mathrm{Ca}^{2+}$ activation and redistribution of cross-bridges upon large mechanical perturbations. For this reason, it is not possible to derive a preferential sequence of force-generation and $\mathrm{P}_{\mathrm{i}}$ release from the force kinetics induced by $\mathrm{P}_{\mathrm{i}}$ jumps (Stehle 2017). As stated before, a limitation to this conclusion is the still unresolved puzzle posed by the asymmetric $\mathrm{P}_{\mathrm{i}}$ jumps found in fast muscle (and slow skeletal muscle at high temperature) that awaits experimental elucidation.

In contrast to slow force kinetics induced by $\left[\mathrm{P}_{\mathrm{i}}\right]$ decrease and large mechanical perturbations, investigations by Lombardi and coworkers show that upon small mechanical perturbations, cross-bridges can rapidly and repeatedly regenerate force uncoupled from $\mathrm{P}_{\mathrm{i}}$ release (Irving et al. 1992; Lombardi et al. 1992; Piazzesi et al. 1997; Caremani et al. 2008, 2013; Linari et al. 2010). In combination, de novo force generation appears to be limited by slow $\mathrm{P}_{\mathrm{i}}$ release, whereas force can be rapidly regenerated independent from $P_{i}$ release. The mechanisms underlying the coupling of $P_{i}$ release and the rate-limiting transition for de novo force generation and the uncoupling of the force-generating step and $\mathrm{P}_{\mathrm{i}}$ release for force re-generation needs still to be clarified. Solving these mechanisms and working towards a unifying concept combining turnover and recovery kinetics is essential for understanding the crossbridge cycle and for developing drugs targeting the rate of skeletal and cardiac muscle contraction.

Acknowledgements RS is grateful for support by the German Research Foundation (FOR1352-TP09) and Köln Fortune (Faculty of Medicine, Cologne). This work was supported by Telethon Italy (GGP16191), Italian Ministry of Health (WFR GR-2011-02350583) and Università degli studi di Firenze (ex-60\%) to CT. The authors thank Dr. Nicoletta Piroddi and Corrado Poggesi for helpful discussions. We acknowledge the seminal work of Prof. Dr. Bernhard Brenner on ratemodulation of $k_{\mathrm{TR}}$ and its impact for the cross-bridge mechanism.

\section{References}

Araujo A, Walker JW (1996) Phosphate release and force generation in cardiac myocytes investigated with caged phosphate and caged calcium. Biophys J 70:2316-2326 
Belus A, Piroddi N, Tesi C (2003) Mechanism of cross-bridge detachment in isometric force relaxation of skeletal and cardiac myofibrils. J Muscle Res Cell Motil 24:261-267

Bershitsky SY, Tsaturyan AK (2002) The elementary force generation process probed by temperature and length perturbations in muscle fibres from the rabbit. J Physiol 540:971-988

Bowater R, Sleep J (1988) Demembranated muscle fibers catalyze a more rapid exchange between phosphate and adenosine triphosphate than actomyosin subfragment 1 . BioChemistry 27:5314-5323

Brenner B (1988) Effect of $\mathrm{Ca}^{2+}$ on cross-bridge turnover kinetics in skinned single rabbit psoas fibers: implications for regulation of muscle contraction. Proc Natl Acad Sci USA 85:3265-3269

Brenner B, Chalovich JM (1999) Kinetics of thin filament activation probed by fluorescence of $N$-((2-(iodoacetoxy)ethyl)- $N$-methyl) amino-7-nitrobenz-2-oxa-1, 3-diazole-labeled troponin I incorporated into skinned fibers of rabbit psoas muscle: implications for regulation of muscle contraction. Biophys J 77:2692-2708

Brenner B, Eisenberg E (1986) Rate of force generation in muscle: correlation with actomyosin ATPase activity in solution. Proc Natl Acad Sci USA 83:3542-3546

Campbell KS (2016) Compliance accelerates relaxation in muscle by allowing myosin heads to move relative to actin. Biophys J 110:661-668

Capitanio M, Canepari M, Cacciafesta P, Lombardi V, Cicchi R, Maffei M, Pavone FS, Bottinelli R (2006) Two independent mechanical events in the interaction cycle of skeletal muscle myosin with actin. Proc Natl Acad Sci USA 103:87-92

Caremani M, Dantzig J, Goldman YE, Lombardi V, Linari M (2008) Effect of inorganic phosphate on the force and number of myosin cross-bridges during the isometric contraction of permeabilized muscle fibers from rabbit psoas. Biophys J 95:5798-5808

Caremani M, Melli L, Dolfi M, Lombardi V, Linari M (2013) The working stroke of the myosin II motor in muscle is not tightly coupled to release of orthophosphate from its active site. J Physiol 591:5187-5205

Caremani M, Melli L, Dolfi M, Lombardi V, Linari M (2015) Force and number of myosin motors during muscle shortening and the coupling with the release of the ATP hydrolysis products. J Physiol 593:3313-3332

Chalovich JM, Eisenberg E (1982) Inhibition of actomyosin ATPase activity by troponin-tropomyosin without blocking the binding of myosin to actin. J Biol Chem 257:2432-2437

Colomo F, Poggesi C, Tesi C (1994) Force responses to rapid length changes in single intact cells from frog heart. J Physiol 475:347-350

Colomo F, Piroddi N, Poggesi C, te Kronnie G, Tesi C (1997) Active and passive forces of isolated myofibrils from cardiac and fast skeletal muscle of the frog. J Physiol 500:535-548

Colomo F, Nencini S, Piroddi N, Poggesi C, Tesi C (1998) Calcium dependence of the apparent rate of force generation in single striated muscle myofibrils activated by rapid solution changes. Adv Exp Med Biol 453:373-381

Cooke R (1997) Actomyosin interaction in striated muscle. Physiol Rev 77:671-697

Cooke R, Franks K, Luciani GB, Pate E (1988) The inhibition of rabbit skeletal muscle contraction by hydrogen ions and phosphate. J Physiol 395:77-97

Coupland ME, Ranatunga KW (2003) Force generation induced by rapid temperature jumps in intact mammalian (rat) skeletal muscle fibres. J Physiol 548:439-449

Dantzig JA, Goldman YE, Millar NC, Lacktis J, Homsher E (1992) Reversal of the cross-bridge force-generating transition by photogeneration of phosphate in rabbit psoas muscle fibres. J Physiol 451:247-278
Davis JS, Rodgers ME (1995) Indirect coupling of phosphate release to de novo tension generation during muscle contraction. Proc Natl Acad Sci USA 92:10482-10486

de Tombe PP, Stienen GJ (2007) Impact of temperature on cross-bridge cycling kinetics in rat myocardium. J Physiol 584:591-600

Dong C, Chen B (2016) Temperature effect on the chemomechanical regulation of substeps within the power stroke of a single Myosin II. Sci Rep 6:19506

Edes IF, Czuriga D, Csanyi G, Chlopicki S, Recchia FA, Borbely A, Galajda Z, Edes I, van der Velden J, Stienen GJ, Papp Z (2007) Rate of tension redevelopment is not modulated by sarcomere length in permeabilized human, murine, and porcine cardiomyocytes. Am J Physiol Regul Integr Comp Physiol 293:R20-29

Edman KA, Flitney FW (1982) Laser diffraction studies of sarcomere dynamics during 'isometric' relaxation in isolated muscle fibres of the frog. J Physiol 329:1-20

Eisenberg E, Greene LE (1980) The relation of muscle biochemistry to muscle physiology. Annu Rev Physiol 42:293-309

Eisenberg E, Hill TL (1985) Muscle contraction and free energy transduction in biological systems. Science 227:999-1006

Finer JT, Simmons RM, Spudich JA (1994) Single myosin molecule mechanics: piconewton forces and nanometre steps. Nature 368:113-119

Ford LE, Huxley AF, Simmons RM (1977) Tension responses to sudden length change in stimulated frog muscle fibres near slack length. J Physiol 269:441-515

Fortune NS, Geeves MA, Ranatunga KW (1991) Tension responses to rapid pressure release in glycerinated rabbit muscle fibers. Proc Natl Acad Sci USA 88:7323-7327

Geeves MA (2016) Review: The ATPase mechanism of myosin and actomyosin. Biopolymers 105:483-491

Geeves MA, Holmes KC (2005) The molecular mechanism of muscle contraction. Adv Protein Chem 71:161-193

Gordon AM, Homsher E, Regnier M (2000) Regulation of contraction in striated muscle. Physiol Rev 80:853-924

Hibberd MG, Webb MR, Goldman YE, Trentham DR (1985a) Oxygen exchange between phosphate and water accompanies calciumregulated ATPase activity of skinned fibers from rabbit skeletal muscle. J Biol Chem 260:3496-3500

Hibberd MG, Dantzig JA, Trentham DR, Goldman YE (1985b) Phosphate release and force generation in skeletal muscle fibers. Science 228:1317-1319

Houdusse A, Sweeney HL (2016) How myosin generates force on actin filaments. Trends Biochem Sci 41:989-997

Huxley AF (1957) Muscle structure and theories of contraction. Prog Biophys Biophys Chem 7:255-318

Huxley HE (2004) Recent X-ray diffraction studies of muscle contraction and their implications. Philos Trans R Soc Lond B Biol Sci 359:1879-1882

Irving M, Lombardi V, Piazzesi G, Ferenczi MA (1992) Myosin head movements are synchronous with the elementary force-generating process in muscle. Nature 357:156-158

Kawai M, Halvorson HR (1991) Two step mechanism of phosphate release and the mechanism of force generation in chemically skinned fibers of rabbit psoas muscle. Biophys J 59:329-342

Kerrick WG, Xu Y (2004) Inorganic phosphate affects the pCa-force relationship more than the $\mathrm{pCa}-\mathrm{ATPase}$ by increasing the rate of dissociation of force generating cross-bridges in skinned fibers from both EDL and soleus muscles of the rat. J Muscle Res Cell Motil 25:107-117

Linari M, Caremani M, Piperio C, Brandt P, Lombardi V (2007) Stiffness and fraction of Myosin motors responsible for active force in permeabilized muscle fibers from rabbit psoas. Biophys $\mathrm{J}$ 92:2476-2490

Linari M, Caremani M, Lombardi V (2010) A kinetic model that explains the effect of inorganic phosphate on the mechanics and 
energetics of isometric contraction of fast skeletal muscle. Proc Biol Sci 277:19-27

Llinas P, Isabet T, Song L, Ropars V, Zong B, Benisty H, Sirigu S, Morris C, Kikuti C, Safer D, Sweeney HL, Houdusse A (2015) How actin initiates the motor activity of myosin. Dev Cell 33:401-412

Lombardi V, Piazzesi G, Linari M (1992) Rapid regeneration of the actin-myosin power stroke in contracting muscle. Nature 355:638-641

Lopez-Davila AJ, Elhamine F, Ruess DF, Papadopoulos S, Iorga B, Kulozik FP, Zittrich S, Solzin J, Pfitzer G, Stehle R (2012) Kinetic mechanism of $\mathrm{Ca}^{2+}$-controlled changes of skeletal troponin I in psoas myofibrils. Biophys J 103:1254-1264

Lymn RW, Taylor EW (1971) Mechanism of adenosine triphosphate hydrolysis by actomyosin. BioChemistry 10:4617-4624

Mansfield C, West TG, Curtin NA, Ferenczi MA (2012) Stretch of contracting cardiac muscle abruptly decreases the rate of phosphate release at high and low calcium. J Biol Chem 287:25696-25705

Mansson A (2016) Actomyosin based contraction: one mechanokinetic model from single molecules to muscle? J Muscle Res Cell Motil 37:181-194

Mansson A, Rassier D, Tsiavaliaris G (2015) Poorly understood aspects of striated muscle contraction. Biomed Res Int 2015:245154

Martin H, Bell MG, Ellis-Davies GC, Barsotti RJ (2004) Activation kinetics of skinned cardiac muscle by laser photolysis of nitrophenyl-EGTA. Biophys J 86:978-990

Mijailovich SM, Kayser-Herold O, Stojanovic B, Nedic D, Irving TC, Geeves MA (2016) Three-dimensional stochastic model of actin-myosin binding in the sarcomere lattice. J Gen Physiol 148:459-488

Mijailovich SM, Nedic D, Svicevic M, Stojanovic B, Walklate J, Ujfalusi Z, Geeves MA (2017) Modeling the actin.myosin ATPase cross-bridge cycle for skeletal and cardiac muscle myosin isoforms. Biophys J 112:984-996

Millar NC, Homsher E (1990) The effect of phosphate and calcium on force generation in glycerinated rabbit skeletal muscle fibers. A steady-state and transient kinetic study. J Biol Chem 265:20234-20240

Millar NC, Homsher E (1992) Kinetics of force generation and phosphate release in skinned rabbit soleus muscle fibers. Am J Physiol 262:C1239-1245

Muretta JM, Rohde JA, Johnsrud DO, Cornea S, Thomas DD (2015) Direct real-time detection of the structural and biochemical events in the myosin power stroke. Proc Natl Acad Sci USA 112:14272-14277

Palmer S, Kentish JC (1998) Roles of $\mathrm{Ca}^{2+}$ and crossbridge kinetics in determining the maximum rates of $\mathrm{Ca}^{2+}$ activation and relaxation in rat and guinea pig skinned trabeculae. Circ Res 83:179-186

Pate E, Cooke R (1989) A model of crossbridge action: the effects of ATP, ADP and $\mathrm{P}_{\mathrm{i}}$. J Muscle Res Cell Motil 10:181-196

Piazzesi G, Linari M, Reconditi M, Vanzi F, Lombardi V (1997) Cross-bridge detachment and attachment following a step stretch imposed on active single frog muscle fibres. J Physiol 498:3-15

Piroddi N, Tesi C, Pellegrino MA, Tobacman LS, Homsher E, Poggesi C (2003) Contractile effects of the exchange of cardiac troponin for fast skeletal troponin in rabbit psoas single myofibrils. J Physiol 552:917-931

Poggesi C, Tesi C, Stehle R (2005) Sarcomeric determinants of striated muscle relaxation kinetics. Pflugers Arch 449:505-517

Potma EJ, van Graas IA, Stienen GJ (1995) Influence of inorganic phosphate and $\mathrm{pH}$ on ATP utilization in fast and slow skeletal muscle fibers. Biophys J 69:2580-2589

Ranatunga KW, Coupland ME, Mutungi G (2002) An asymmetry in the phosphate dependence of tension transients induced by length perturbation in mammalian (rabbit psoas) muscle fibres. J Physiol 542:899-910
Regnier M, Homsher E (1998) The effect of ATP analogs on posthydrolytic and force development steps in skinned skeletal muscle fibers. Biophys J 74:3059-3071

Regnier M, Morris C, Homsher E (1995) Regulation of the crossbridge transition from a weakly to strongly bound state in skinned rabbit muscle fibers. Am J Physiol 269:C1532-C1539

Siththanandan VB, Donnelly JL, Ferenczi MA (2006) Effect of strain on actomyosin kinetics in isometric muscle fibers. Biophys $\mathbf{J}$ 90:3653-3665

Smith DA (2014) A new mechanokinetic model for muscle contraction, where force and movement are triggered by phosphate release. J Muscle Res Cell Motil 35:295-306

Smith D, Sleep J (2006) Strain-dependent kinetics of the myosin working stroke, and how they could be probed with optical-trap experiments. Biophys J 91:3359-3369

Solzin J, Iorga B, Sierakowski E, Gomez Alcazar DP, Ruess DF, Kubacki T, Zittrich S, Blaudeck N, Pfitzer G, Stehle R (2007) Kinetic mechanism of the $\mathrm{Ca}^{2+}$-dependent switch-on and switchoff of cardiac troponin in myofibrils. Biophys J 93:3917-3931

Steffen W, Sleep J (2004) Using optical tweezers to relate the chemical and mechanical cross-bridge cycles. Philos Trans R Soc Lond B Biol Sci 359:1857-1865

Stehle R (2017) Force responses and sarcomere dynamics of cardiac myofibrils induced by rapid changes in $\left[\mathrm{P}_{\mathrm{i}}\right]$. Biophys $\mathrm{J}$ 112:356-367

Stehle R, Kruger M, Scherer P, Brixius K, Schwinger RH, Pfitzer G (2002a) Isometric force kinetics upon rapid activation and relaxation of mouse, guinea pig and human heart muscle studied on the subcellular myofibrillar level. Basic Res Cardiol 97:I127-I135

Stehle R, Kruger M, Pfitzer G (2002b) Force kinetics and individual sarcomere dynamics in cardiac myofibrils after rapid $\mathrm{Ca}^{2+}$ changes. Biophys J 83:2152-2161

Stehle R, Solzin J, Iorga B, Poggesi C (2009) Insights into the kinetics of $\mathrm{Ca}^{2+}$-regulated contraction and relaxation from myofibril studies. Pflugers Arch 458:337-357

Takagi Y, Shuman H, Goldman YE (2004) Coupling between phosphate release and force generation in muscle actomyosin. Philos Trans R Soc Lond B Biol Sci 359:1913-1920

Telley IA, Denoth J (2007) Sarcomere dynamics during muscular contraction and their implications to muscle function. J Muscle Res Cell Motil 28:89-104

Telley IA, Denoth J, Stussi E, Pfitzer G, Stehle R (2006) Half-sarcomere dynamics in myofibrils during activation and relaxation studied by tracking fluorescent markers. Biophys J 90:514-530

Tesi C, Colomo F, Nencini S, Piroddi N, Poggesi C (2000) The effect of inorganic phosphate on force generation in single myofibrils from rabbit skeletal muscle. Biophys J 78:3081-3092

Tesi C, Colomo F, Piroddi N, Poggesi C (2002a) Characterization of the cross-bridge force-generating step using inorganic phosphate and BDM in myofibrils from rabbit skeletal muscles. J Physiol 541:187-199

Tesi C, Piroddi N, Colomo F, Poggesi C (2002b) Relaxation kinetics following sudden $\mathrm{Ca}^{2+}$ reduction in single myofibrils from skeletal muscle. Biophys J 83:2142-2151

Thomas DD, Kast D, Korman VL (2009) Site-directed spectroscopic probes of actomyosin structural dynamics. Annu Rev Biophys 38:347-369

Trentham DR, Bardsley RG, Eccleston JF, Weeds AG (1972) Elementary processes of the magnesium ion-dependent adenosine triphosphatase activity of heavy meromyosin. A transient kinetic approach to the study of kinases and adenosine triphosphatases and a colorimetric inorganic phosphate assay in situ. Biochem $\mathbf{J}$ 126:635-644

Veigel C, Bartoo ML, White DC, Sparrow JC, Molloy JE (1998) The stiffness of rabbit skeletal actomyosin cross-bridges determined with an optical tweezers transducer. Biophys J 75:1424-1438 
Wahr PA, Rall JA (1997) Role of calcium and cross bridges in determining rate of force development in frog muscle fibers. Am J Physiol 272:C1664-1671

Wahr PA, Cantor HC, Metzger JM (1997) Nucleotide-dependent contractile properties of $\mathrm{Ca}^{2+}$-activated fast and slow skeletal muscle fibers. Biophys J 72:822-834

Walker JW, Lu Z, Moss RL (1992) Effects of $\mathrm{Ca}^{2+}$ on the kinetics of phosphate release in skeletal muscle. J Biol Chem 267:2459-2466

Wang L, Kawai M (2013) A re-interpretation of the rate of tension redevelopment $\mathrm{k}_{\mathrm{TR}}$ in active muscle. J Muscle Res Cell Motil $34: 407-415$
Webb MR, Hibberd MG, Goldman YE, Trentham DR (1986) Oxygen exchange between $\mathrm{P}_{\mathrm{i}}$ in the medium and water during ATP hydrolysis mediated by skinned fibers from rabbit skeletal muscle. Evidence for $\mathrm{P}_{\mathrm{i}}$ binding to a force-generating state. J Biol Chem 261:15557-15564

Yount RG, Lawson D, Rayment I (1995) Is myosin a "back door" enzyme? Biophys J 68:44S-47S (discussion 47S-49S) 